\title{
REVIEW
}

\section{Glycocalyx Degradation in Ischemia-Reperfusion Injury}

Zaid Abassi, ${ }^{* \dagger}$ Zaher Armaly, ${ }^{\ddagger}$ and Samuel N. Heyman ${ }^{\S}$

From the Department of Physiology, ${ }^{*}$ The Ruth \& Bruce Rappaport Faculty of Medicine, Technion-Israeli Institute of Technology, Haifa; Laboratory Medicine, ${ }^{\dagger}$ Rambam Health Campus, Haifa; the Department of Nephrology, ${ }^{\ddagger}$ Nazareth Hospital, Nazareth, Azrieli Faculty of Medicine-Bar Ilan University, Jerusalem; and the Department of Medicine, ${ }^{\S}$ Hadassah Hebrew University Hospital, Mt. Scopus, Jerusalem, Israel

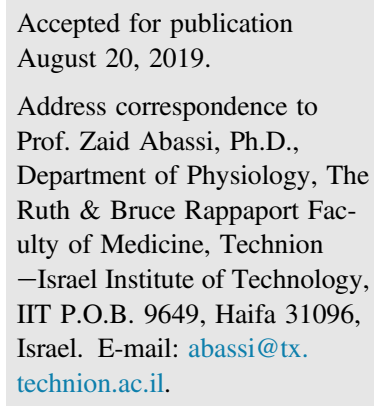

\begin{abstract}
The glycocalyx is a layer coating the luminal surface of vascular endothelial cells. It is vital for endothelial function as it participates in microvascular reactivity, endothelium interaction with blood constituents, and vascular permeability. Structural and functional damage to glycocalyx occurs in various disease states. A prominent clinical situation characterized by glycocalyx derangement is ischemiareperfusion (I/R) of the whole body as well as during selective I/R to organs such as the kidney, heart, lung, or liver. Degradation of the glycocalyx is now considered a cornerstone in I/R-related endothelial dysfunction, which further impairs local microcirculation with a feed-forward loop of organ damage, due to vasoconstriction, leukocyte adherence, and activation of the immune response. Glycocalyx damage during $I / R$ is evidenced by rising plasma levels of its principal constituents, heparan sulfate and syndecan-1. By contrast, the concentrations of these compounds in the circulation decrease after successful protective interventions in $I / R$, suggesting their use as surrogate biomarkers of endothelial integrity. In light of the importance of the glycocalyx in preserving endothelial cell integrity and its involvement in pathologic conditions, several promising therapeutic strategies to restore the damaged glycocalyx and to attenuate its deleterious consequences have been suggested. This review focuses on alterations of glycocalyx during I/R injury in general (to vital organs in particular), and on maneuvers aimed at glycocalyx recovery during I/R injury. (Am J Pathol 2020, 190: 752-767; https://doi.org/ 10.1016/j.ajpath.2019.08.019)
\end{abstract}

Protracted but reversible interruptions in blood supply and tissue oxygenation lead to organ damage, termed ischemiareperfusion (I/R) injury. Initially it reflects exhausting cellular energy stores. ${ }^{1,2}$ Depletion of ATP and of creatine phosphate in skeletal muscle and brain alters ion channel function, which may further intensify the depletion of energy stores, for instance, by increasing cytosolic $\left[\mathrm{Ca}^{2+}\right]$ and enhancing actin-myosin energy-requiring interaction in muscle. ${ }^{1,2}$ In other tissues, energy-consuming adaptive and reparative cellular responses may be activated, including those leading to programed cell death. Resumed oxygen supply fuels intensified the production of reactive oxygen species (ROS), even when suboptimal and transient. Both oxygen deprivation and enhanced generation of ROS lead to cellular metabolic disturbances, membrane damage, altered membrane permeability, and organellar dysfunction, ultimately resulting in cell death. ${ }^{1,2}$

$\mathrm{I} / \mathrm{R}$ injury is a well-known phenomenon in many clinical settings, with prompt interruptions in blood flow and tissue oxygenation, such as during acute myocardial infarction; after embolic events involving limbs, kidneys, brain, or intestine segments; or in harvested and transplanted organs. Profound hypotension or intense systemic or regional inflammation may also lead to the development of $\mathrm{I} / \mathrm{R}$ injury. ${ }^{3}$

Supported by Israel Ministry of Health grant 3-00000-6156 (Z.Ab.) Disclosures: None declared.

This article is part of a review series on glycocalyx in human disease. 
Importantly, I/R injury may also affect blood vessels, which may further compromise organ parenchymal integrity. Indeed, microvascular injury plays an important role in I/R injury (Figure 1). It leads to altered vascular reactivity and to a leaky endothelium with the formation of interstitial edema and rising hydrostatic pressure that alters regional microcirculation and oxygen diffusion. Moreover, the adhesion of platelets and white blood cells to injured endothelium, as well as the local activation of the coagulation system, lead to the plugging of capillaries, which further intensifies tissue hypoxia and $\mathrm{I} / \mathrm{R}$ injury.

Vascular endothelial cells are lined with glycocalyx, consisting of membrane-bound proteoglycans, glycosaminoglycans, and sialic acid-containing glycoproteins (Figure 2). The glycocalyx is highly important in endothelial function, as it is involved in microvascular reactivity and modulates interaction of the endothelium with blood constituents. On one hand, it protects the endothelial cell from shear stress caused by blood flow and serves as a vascular permeability barrier. Yet, it harbors various chemokines, receptors, growth factors, and enzymes [including extracellular superoxide dismutase, endothelial nitric oxide synthase (eNOS), angiotensin-converting enzyme, lipoprotein lipase, xanthine oxidase, and antithrombin III] that play a central role in endothelial function and blood/vascular/tissue interactions. There is emerging evidence indicating a tight functional connection between mechanotransducing

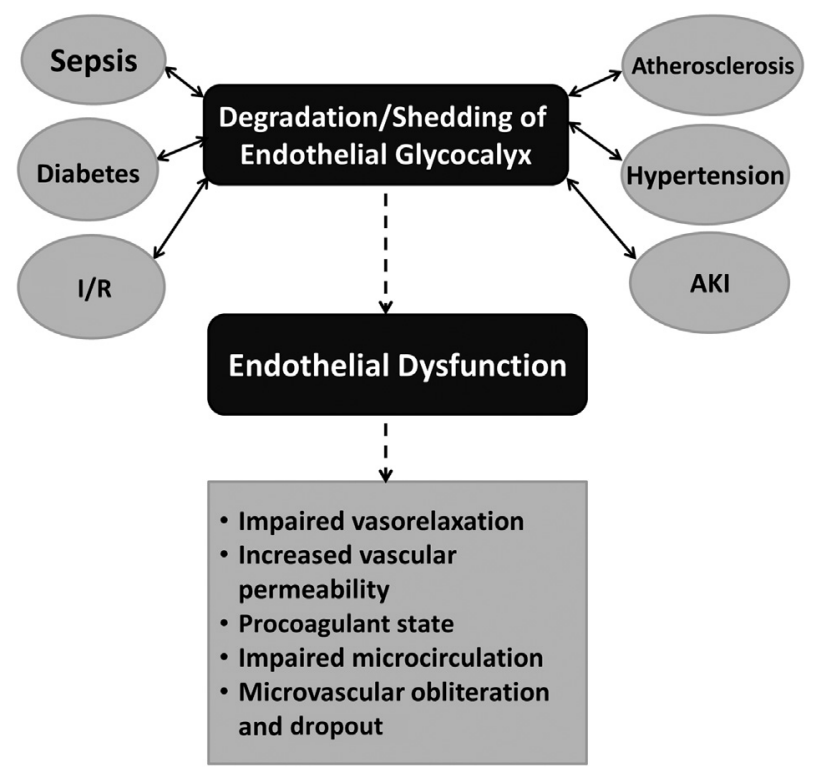

Figure 1 Impact of chronic and acute illnesses on structural and functional damage to glycocalyx. Glycocalyx shedding occurs in sepsis, global and regional $I / R$, diabetes mellitus, hypertension, atherosclerosis, and others. Degradation of the glycocalyx is now considered a cornerstone in the pathogenesis of clinical settings characterized by endothelial dysfunction, which further impairs the local microcirculation with a feedforward loop of organ damage, as evident by impaired vasorelaxation, increased vascular permeability, procoagulant state, impaired microcirculation, and microvascular obliteration and dropout. AKI, acute kidney injury. properties of glycocalyx and eNOS activity. ${ }^{4}$ Of note, in one study, the application of shear stress to cultured endothelial cells led to enhanced 4-amino-5-methylamino-2',7'-difluorofluorescein (DAF-FM) fluorescent, a reagent used for detecting NO production, as compared to its levels in the same cells before force application. The interplay between eNOS and glycocalyx is further supported by the finding that the enhancement of nitric oxide production was completely blocked by the removal of endothelial glycocalyx (EG) components by the treatment of endothelial cells with heparanases I and III and hyaluronidase, comparable to the effects of $N(\omega)$-nitro-L-arginine methyl ester, an eNOS inhibitor. ${ }^{4}$ The data suggest that the increased nitric oxide production is specific to eNOS and that an intact EG is required for proper eNOS function. Furthermore, these findings may indicate potential cooperation between the glycocalyx and the endothelium in inducing the endothelial dysfunction that characterizes diverse cardiovascular, renal, and metabolic diseases. ${ }^{4}$

$\mathrm{I} / \mathrm{R}$ injury leads to rapid dismantling of the microvascular glycocalyx in all tissues. In fact, degradation of the glycocalyx might be the earliest form of structural damage in I/ $\mathrm{R},{ }^{5}$ as clearly demonstrated in the setting of acute myocardial infarction and cardiac interventions, both in experimental $^{6,7}$ and clinical settings ${ }^{8,9}$ (Figure 2). Damaged glycocalyx has also been documented after major aortic surgery ${ }^{10}$ or prolonged intra-aortic balloon inflation with subsequent reperfusion in pigs $^{11}$; after experimental and clinical hepatic I/R injury ${ }^{12}$; and after pulmonary, ${ }^{13,14}$ liver, ${ }^{15}$ and renal transplantation, ${ }^{16}$ with rising plasma levels of heparan sulfate (HS) and syndecan (SYND)-1, the principal constituents of glycocalyx. Efflux of these compounds was also noticed and used as a marker of successful protective interventions in isolated hearts or livers after I/ R. ${ }^{17-19}$ Moreover, intact glycocalyx in hepatic sinusoids and in the intestinal mucosa has been included as one of the markers of efficacy in a recent study exploring a novel blood substitute for severe hemorrhagic shock in pigs. ${ }^{20}$

The current review summarizes the contribution of glycocalyx to the progression of $\mathrm{I} / \mathrm{R}$ injury in major clinical settings.

\section{Clinical Conditions with I/R Associated with Glycocalyx Degradation}

\section{Global Whole-Body Ischemia}

Global ischemia occurs in various clinical settings, such as cardiac arrest, repair of aortic aneurysm, hemorrhagic shock in trauma, or ST-elevation myocardial infarction complicated by cardiogenic shock. ${ }^{10,21,22}$ During these grave hemodynamically compromised situations, distortion of glycocalyx structure and function contributes to the multiorgan dysfunction that follows global ischemia of various etiologies (Figure 2). In all of these clinical situations, plasma levels of both SYND-1 and HS, the major 


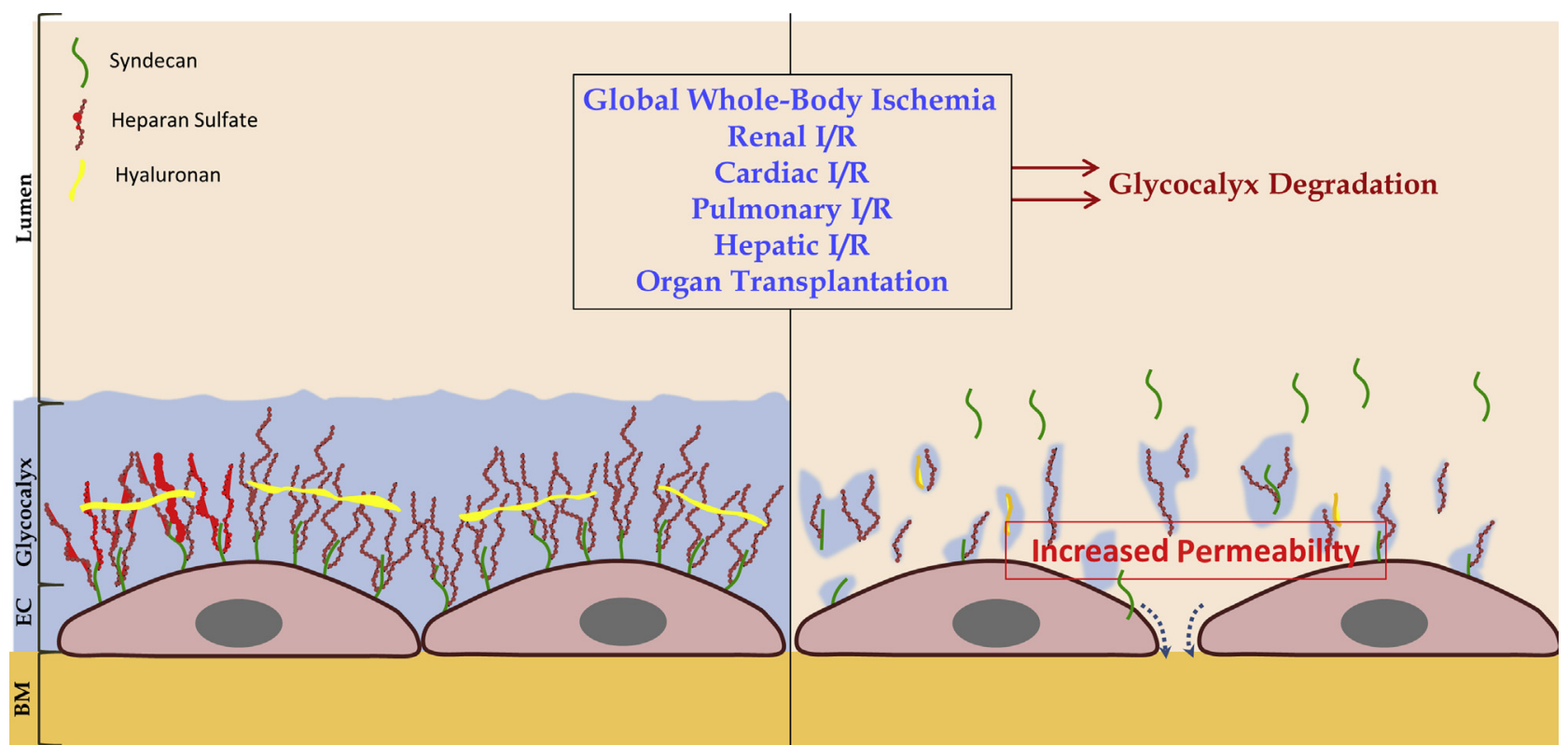

Figure 2 Endothelium glycocalyx erosion under ischemia reperfusion conditions. One of the most prominent clinical situations characterized by glycocalyx derangement is $I / R$ of the whole body as well as during selective I/R to organs such as the kidney, heart, lung, or liver. Under such circumstances, sudden interruption of blood flow and tissue oxygenation provokes increased membranal permeability and ultimately induces cellular injury. Resumed oxygen supply upon reperfusion enhances the generation of reactive oxygen species, which contributes to this phenomenon and specifically leads to glycocalyx damage. EC, endothelial cell.

components of glycocalyx, are elevated. ${ }^{10}$ Specifically, in one study, the plasma levels of SYND-1 and HS increased 42- and 10-fold, respectively, when global ischemia was induced by circulatory arrest. ${ }^{10}$ Interestingly, while plasma concentrations of these compounds rose 65- and 19-fold during regional ischemia of heart and lungs after cardiopulmonary bypass $(\mathrm{CPB})$, the increases were moderate (15and 3-fold) after infrarenal ischemia, ${ }^{10}$ likely reflecting more restricted, lower-body endovascular damage. To track the origins of SYND-1 and HS, investigators applied an experimental model of guinea pig hearts with and without global ischemia. Electron microscopy revealed shedding of the glycocalyx after global warm cardiac ischemia for 20 minutes. Erosion of the glycocalyx was further documented by a concurrent increase in SYND-1 and HS levels in coronary effluent and subsequently in the circulation. ${ }^{10}$ Furthermore, immunohistochemical staining of SYND-1 and HS in the aorta revealed down-regulation of these substances, ${ }^{10}$ suggesting an endothelial lining origin, including that of the coronary vessels. Global ischemia likely causes generalized endothelial injury in various organs, which most likely contributes to the overall elevated levels of plasma SYND-1 and HS under this condition. Support for this concept derives from the observation that glycocalyx degradation takes place in experimental hemorrhagic shock, a model of general hypoxia-reperfusion. ${ }^{23,24}$ Massive bleeding along with profound hypoxia is a common clinical situation, especially in major surgeries and polytrauma. Indeed, degradation of glycocalyx occurs in trauma patients. ${ }^{25,26}$ Although hypoxia may underlie this deleterious impact on glycocalyx, the contribution of the inflammatory response to the reduction of glycocalyx dimension under these circumstances could not be ruled out. ${ }^{27}$ In line with this assumption, both plasma SYND-1 and HS biomarkers were elevated in patients with hemorrhagic shock and multiple trauma along with high levels of inflammatory indicators and aberrance of the coagulation system. ${ }^{25}$

\section{Renal I/R Injury}

Acute kidney injury (AKI) may develop due to ischemic, nephrotoxic, or septic insults or with their combinations, leading to an abrupt impairment in kidney function, as evident by a sharp decline in glomerular filtration rate and excretory renal functions. ${ }^{28}$

Experimental renal warm I/R injury is well characterized and pathophysiologically parallels that of cardiac $I / R$, for instance, including evidence of glycocalyx injury. Yet, it likely bears little relevance to human hypoxic AKI, which most commonly arises in a functioning kidney due to mismatched oxygen supply and demand, particularly in the outer medulla. ${ }^{3}$ In this region, a limited blood supply via vasa recta (required for the urinary concentrating capacity) hardly suffices for intense local tubular transport and oxygen expenditure, leading to a physiologically low $\mathrm{pO}_{2}$ under normal conditions. ${ }^{29}$ Hypoxic medullary injury may develop when the delicate balance of regional oxygen supply and demand is altered, for instance with the administration of nonsteroidal anti-inflammatory drugs, 
which selectively reduce medullary blood flow and disinhibit $\mathrm{Na} / \mathrm{K} / \mathrm{ATPase}$ activity in ascending limb of the loop of Henle. At the histologic level, the most prominent morphologic perturbations in nephrotoxic AKI and after warm I/R are loss of brush border and desquamation of proximal tubular epithelial cells and cast formation, that is, hyaline and granular and pigmented tubular casts, particularly in distal and collecting ducts. Hypoxic renal medullary injury, which forms the majority of hypoxic AKI cases, usually appears as focal dropout of tubular cells, principally of ascending limb of the loop of Henle, an injury pattern most often missed in kidney biopsies. ${ }^{3,30}$ These changes are associated with a profound decrease in glomerular filtration rate, mostly due the activation of tubuloglomerular feedback, and to vasoconstriction and elevation of intratubular hydrostatic pressure, resulting in tubulorrhexis and backleak of tubular fluid. ${ }^{28}$ Due to the complex and pathogenetically heterogeneous nature of AKI, there is no clear-cut and universal rational therapy for the disease.

There is increasing evidence that implicates the degradation of EG in the pathogenesis of nephrotoxic AKI and after I/ $\mathbf{R}^{31,32}$ (Figures 1 and 2). Yet, endothelial dysfunction and damaged glycocalyx in the renal microvasculature likely appear even without frank global ischemia and reperfusion under extreme settings of severe and protracted renal hypoxia, evidenced in experimental settings ${ }^{33}$ and in humans ${ }^{3}$ and manifested as injured peritubular capillaries, congestion, and interstitial hemorrhage. Thus, these observations likely bear relevance in both hypoxic AKI with medullary injury and renal I/R. Glycocalyx damage may explain, at least in part, one of the hallmarks of AKI, namely the renal hemodynamic and microvascular impairment, and may justify the promising attempts to restore EG as a novel therapeutic tool to ameliorate AKI. Specifically, experimental studies clearly indicate that ischemia provokes alterations in endothelial function and eventually the degree and severity of AKI. ${ }^{34}$ Intrinsic damage to the endothelium results in the impairment of the homeostatic response in vascular tone, promotes leukocyte adhesion, and exacerbates renal hypoperfusion. Moreover, AKI is characterized by low kidney capillary density, which stems from impaired endothelial growth responses and eventually leads to progressive chronic kidney disease. Endothelial cells also form one of the three layers constituting the glomerular barrier besides the basement membrane and epithelial cells (podocytes). ${ }^{35}$ Despite the fact that the endothelium of the glomerular capillaries is fenestrated and has high hydraulic conductivity, it is important in preventing filtering of blood cells and large molecules, including plasma proteins. Besides its role as a physical barrier, the endothelial surface layer is negatively charged at the basement membrane, ${ }^{36-38}$ thus contributing to the retention of negatively charged plasma proteins at physiological $\mathrm{pH}$. The relevance of the glycocalyx to the integrity of the glomerular barrier is widely recognized, as the removal or loss of these proteins, in either the glomerulus or after more generalized endothelial damage, has been associated with proteinuria in various experimental models. ${ }^{38,39}$ At the clinical level, kidney diseases of various etiologies are thought to involve the glycocalyx, as derangements of this layer have been documented. ${ }^{40,41}$ Moreover, uremia per se leads to damage to the glycocalyx in all organs: Sidestream darkfield imaging of the sublingual microcirculation has revealed that dialysis patients exhibit shedding of the glycocalyx, resulting in a reduction in its thickness. ${ }^{42}$ Moreover, these patients have increased perfused boundary region and perfused diameters of sublingual microcirculation, consistent with deeper penetration of erythrocytes into glycocalyx, indicating a loss of glycocalyx barrier properties. In addition, dialytic patients have higher serum levels of the glycocalyx constituents hyaluronan and SYND-1 and increased hyaluronidase activity, suggesting the shedding of these components. ${ }^{42}$ It should be emphasized that patients on dialysis may experience intradialytic hypotension, which is largely involved in the rapid loss of residual renal function, probably due to perturbation in vascular tone, although shedding of the glomerular microvascular glycocalyx could not be excluded, as is the case in various ischemic insults. Indeed, a loss of residual renal function has been associated with greater shedding of hyaluronan in the blood. ${ }^{41}$ Notably, patients with higher degrees of inflammation have been found to have more significant damage to the glycocalyx barrier. ${ }^{43}$ In line with the importance of glycocalyx in maintaining vascular integrity in general and in renal physiology in particular, and with the impact of kidney failure on glycocalyx integrity, successful kidney transplantation from a living donor is characterized by normal glycocalyx dimensions comparable to those measured in normal levels. ${ }^{44}$ Furthermore, successful transplantation has not been associated with elevated levels of soluble thrombomodulin or SYND-1 in the blood, as in transplant recipients who develop interstitial fibrosis and tubular atrophy.

\section{Cardiac I/R Damage}

Glycocalyx degradation has been explicitly documented in acute myocardial infarction and cardiac interventions, both in experimental ${ }^{6,7}$ and clinical settings ${ }^{8,9}$ (Figure 2). For instance, both ischemia and hypoxia with reperfusion/ reoxygenation resulted in enhanced release of SYND-1 and HS in coronary effluent of isolated guinea pig hearts. ${ }^{45}$ The authors suggested that purine-mediated degranulation of resident mast cells, with liberated tryptase $\beta$ acting as potential sheddase, may be involved in glycocalyx degradation. Support for this notion came from a comparable study by Becker et $\mathrm{al}^{46}{ }^{46}$ using isolated guinea pig hearts, demonstrating glycocalyx injury after $\mathrm{I} / \mathrm{R}$ and hypoxia/ reoxygenation. Studies in the heart have provided most information regarding the pathogenesis of glycocalyx degradation after I/R injury. Inosine, which accumulates in the interstitial fluid of hypoxic and postischemic hearts due to exaggerated degradation of ATP/ADP, was implicated in the activation of mast cells via stimulation of A3-type receptors. ${ }^{46}$ Notably, mast cells are mobilized to ischemic and 
inflamed tissues, including the myocardium and kidney, ${ }^{47}$ where they play a role in organ injury and remodeling, likely via chymase, a key enzyme in local angiotensin II generation and transforming growth factor $\beta$ activation. ${ }^{47}$ Moreover, mast cells contain large amounts of cytokines and chemokines and express heparanase, which is secreted by these cells and contributes to extracellular matrix remodeling, including glycocalyx shedding. ${ }^{48,49}$

Evidence that a similar phenomenon occurs at the clinical level was derived from the observations that CPB, cardioplegia, and repair of aortic aneurysms are associated with elevated levels of circulatory SYND-1, HS, and occasionally hyaluronan, reflecting shedding of these components from the glycocalyx. ${ }^{9,10,50}$ Derangement of the latter may underlie the enhanced permeability of the microvascular bed in the cardiac tissue and the exaggerated leukocyte and platelet adhesion to the capillary wall after reperfusion, leading to tissue edema, to the formation of platelet aggregates, and eventually to vascular plugging. ${ }^{51}$ Moreover, glycocalyx shedding contributes to the impaired vasorelaxation and predisposition to the no-flow phenomenon, a common complication in vascular manipulations and renal I/ $\mathrm{R}^{52,53}$ Comparable elevations in SYND-1 and HS occur after on-pump CPB and in off-pump coronary bypass operations, ${ }^{9}$ despite an anticipated minimal cardiac ischemia with the latter technique, suggesting that additional factors besides ischemia may be involved in glycocalyx shedding. One explanation might be that the elevated SYND-1 and HS could originate from systemic sources, as this major surgery is associated with cardiac mechanical stress, generalized vascular trauma, and an inflammatory response, all known to enhance glycocalyx shedding and endothelial dysfunction. In this context, plasma levels of the glycocalyx components SYND-1, HS, and hyaluronic acid increased approximately two- to threefold in patients surviving cardiac arrest at different phases of post-cardiac arrest syndrome, as compared to hemodynamically stable patients with acute coronary syndrome who served as controls. ${ }^{54}$ As mentioned in the previous paragraph, systemic inflammatory response may be a major contributor to the elevated circulating biomarkers of glycocalyx damage (SYND-1 and HS) after I/R. For instance, CPB surgery provokes a remarkable systemic inflammatory response, as evident by peaked proinflammatory cytokines, infiltration of immune cell into various organs, activation of the coagulation system and complement pathway, and recruitment of inflammatory cells in multiple organs, with oxidative stress and endothelial dysfunction. ${ }^{55}$ The latter aggravates the translocation of bacterial toxins from the intestine to the circulation, thus accelerating the inflammatory response. ${ }^{56}$ It is therefore appealing to assume that CBP shares some immunologic aspects of sepsis, a clinical situation characterized by clearcut evidence of glycocalyx degradation. ${ }^{43}$ Tumor necrosis factor (TNF)- $\alpha$ is likely a common potential mediator of the immunologic response and subsequent glycocalyx injury during $\mathrm{CPB}$ and sepsis, as its levels have been reported to be increased in both clinical settings. Indeed, the administration of TNF- $\alpha$ into isolated hearts promoted massive destruction of glycocalyx, whereas pretreatment with hydrocortisone or antithrombin abolished this adverse outcome. $^{57}$ Interestingly, the neutralization of TNF- $\alpha$ attenuated glycocalyx shedding in clinical sepsis, ${ }^{58}$ suggesting a role for this cytokine in the local and systemic shedding of glycocalyx.

Atrial natriuretic peptide is an additional factor that may cause glycocalyx damage. Atrial natriuretic peptide is secreted in response to fluid overload and during cardiac stress. ${ }^{59}$ Its infusion to isolated guinea pig hearts was reported to cause rapid shedding of individual components (SYND-1) of the glycocalyx and led to histologically detectable degradation. ${ }^{60}$ At the clinical level, volume expansion before elective surgery with colloid solution, but not by normovolemic hemodilution, enhanced atrial natriuretic peptide levels along with disruption of the glycocalyx, as was evident by enhanced shedding of SYND-1 and hyaluronic acid. ${ }^{61,62}$ These results suggest that changes in the integrity of the EG may underlie the stimulatory effect of atrial natriuretic peptide on vascular permeability.

\section{Pulmonary I/R Damage}

As in other tissues, glycocalyx contributes to lung health and disease. ${ }^{63}$ Specifically, this layer is essential for the normal development of alveoli, as was learned from null mutants of Giardia lamblia actin 1, exostosins 1 and 2, which encode enzymes that build the initial unmodified HS proteoglycan (HSPG). Likewise, transgenic animal studies have demonstrated the importance of HS to proper organ development. ${ }^{63}$ The glycocalyx of the pulmonary vasculature is unique, as it is thicker than that of other organs, ${ }^{64}$ perhaps underlining its importance in preventing interstitial edema and homing of leukocytes. Moreover, there is significant heterogeneity of HS sulfation across different compartments within the lung, potentially reflecting context-specific contributions of this glycosaminoglycan to pulmonary function. ${ }^{65}$ Immunofluorescence and mass spectrometry revealed the presence of HS and chondroitin sulfate within the lung epithelial glycocalyx. ${ }^{63}$ Although most studies have addressed the devastating impact of sepsis on the integrity of glycocalyx, ${ }^{66}$ there are scarce reports concerning its status after pulmonary I/R (Figure 2). Yet, degradation of the glycocalyx likely contributes to the high morbidity and mortality in this clinical setting, as it is involved in pulmonary dysfunction after I/R. Indeed, experimental studies in pulmonary autotransplantation models ${ }^{14}$ disclosed glycocalyx degradation, as evidenced by elevated plasma levels of SYND-1 and HS (Figure 2).

Lung injury may also occur after hemorrhagic shock and after ST-elevation myocardial infarction complicated by cardiogenic shock, which cause generalized ischemia, shedding of the glycocalyx, and endothelial injury. ${ }^{21,22}$ Similarly, various cardiovascular surgeries, including CPB 
and operations of infrarenal aortic aneurysms, induce a reduction in pulmonary glycocalyx thickness along with elevated levels of plasma SYND-1 and HS. The most prominent elevation in the circulatory levels of these glycocalyx components was observed after global ischemia, as in circulatory arrest, regional ischemia of heart and lungs after $\mathrm{CPB}$, and infrarenal ischemia. ${ }^{62,67}$

It is well known that disruption of glycocalyx contributes to neutrophil activation and adhesion, a hallmark of pulmonary injury of various etiologies, including $\mathrm{I} / \mathrm{R} .{ }^{68}$ These cells contain serine proteases, elastase, and proteinase-3, which degrade certain components of the glycocalyx along with up-regulated heparanase. ${ }^{22}$

\section{Hepatic I/R Damage}

Derangement of glycocalyx structure and function have been documented after experimental and clinical hepatic I/R injury (Figure 2). The latter occurs in major liver surgery, including liver resection or transplantation, which may progress to liver failure. ${ }^{12,69,70}$ As in the case with other organs subjected to $\mathrm{I} / \mathrm{R}$, the main inflicted hepatic and microvascular damage is attributed to overproduction of ROS and reactive nitrogen species during I/R. $.^{12,71,72} \mathrm{He}-$ patic glycocalyx is specifically prone to oxidative injury, which in turn exacerbates $\mathrm{I} / \mathrm{R}$ damage, as evident by enhanced vasoconstriction, leukocyte adherence, and activation of innate immune cells. ${ }^{12,72,73}$ Most of the information in this regard was derived from major liver surgery in patients, and to a lesser extent from experimental models of hepatic I/R. ${ }^{12,73}$ In one such model, hepatic I/R for $60 \mathrm{mi}-$ nutes in C57BL/6J mice was found to induce glycocalyx degradation, with HS being released into the circulation, peaking at 1 hour after reperfusion and sustained for an additional 6 hours, serving as a surrogate marker for glycocalyx shedding. ${ }^{12}$ Likewise, I/R in Sprague Dawley rats for 45 minutes resulted in a time-related elevation of plasma levels of HS and SYND-1 along with liver enzymes. ${ }^{19}$ Liver tissues exhibited sinusoidal congestion after I/R, in association with a substantially damaged EG. ${ }^{19}$

At the clinical level, circulating HS concentrations were elevated in patients subjected to major liver resection with transient vascular inflow occlusion. ${ }^{15}$ However, a similar increase in plasma HS was observed in a subgroup of patients that underwent major hepatic or other surgical procedures but without $\mathrm{I} / \mathrm{R}^{12,74,75}$, suggesting that other mechanisms could alter the glycocalyx in hepatic microvascular endothelial cells. It should be emphasized that comparable puzzling observations were encountered in both CPB and after aortic clamping, in which increases in plasma HS and SYND-1 occurred regardless of the duration of ischemia. $^{50,76}$ The mechanisms underlying this increase in HS, other than I/R, may involve inflammatory response, as HS fragments activate peripheral blood mononuclear cells via Toll-like receptor 4 receptors, coupled with activation of $\mathrm{NF}-\mathrm{KB}$, and eventually up-regulation of cytokine production/release, including IL-1 $\beta,-6,-8$, and -10 and TNF. ${ }^{12,77}$ Moreover, hepatic $\mathrm{I} / \mathrm{R}$ is characterized by the accumulation of platelets and the formation of blood clots, along with the release of heparanase into the circulation, resulting in glycocalyx erosion. The latter phenomenon has been associated with a declining content of anticoagulants on the endothelial surface, such as HS, antithrombin III, and tissue factor pathway inhibitor, thus promoting coagulation. ${ }^{9,78}$ Collectively, this interplay between heparanase and glycocalyx degradation represents a vicious cycle, in which hepatic hypoxia, oxidative stress, release of damageassociated molecular patterns from injured cells, ${ }^{9}$ and thrombosis up-regulate heparanase, whereas the latter intensifies its stimulators, yielding a cumulative threat to glycocalyx integrity ${ }^{12}$ (Figure 3 ).

\section{Involvement of Glycocalyx in the Pathogenesis of I/R Damage in Transplanted Organs}

Since kidney transplantation is associated with renal I/R, ${ }^{79}$ it is appealing to assume that the heparanase/HSPG system is involved in the pathogenesis of delayed graft function and chronic allograft nephropathy (Figure 2). Indirect support for this notion is derived from the observation that heparanase plays a key role in epithelial-mesenchymal transition and macrophage polarization after renal I/R damage. ${ }^{31,80} \mathrm{In}$ this context, Barbas et $\mathrm{al}^{74}$ showed that HS is a novel biomarker of acute cellular rejection, released from the extracellular matrix via the enzymatic action of heparanase during T-cell infiltration of graft tissue. Specifically, plasma HS levels were increased significantly in kidney transplant human recipients with biopsy-proved acute cellular rejection compared with healthy controls, recipients with stable graft function, and recipients without acute cellular rejection on biopsy. ${ }^{74}$ Similarly, high blood levels of HS were found in a murine model of rejected cardiac allografts, along with upregulation of heparanase expression in activated $\mathrm{T}$ cells. ${ }^{74}$ The expression levels of SYND-1, a transmembrane HSPG, SYND-1 sheddases (a disintegrin and metalloprotease domain 17, matrix metalloproteinase 9), and heparanase were all significantly up-regulated after renal transplantation. ${ }^{75,81}$ Increased epithelial SYND-1 in allografts was correlated with low proteinuria and reduced serum creatinine, with a more limited interstitial inflammation and tubular atrophy, and with prolonged allograft survival. ${ }^{81}$ On the other hand, Chen et al ${ }^{82}$ reported that the transplantation of renal allografts with conditional glycocalyx-modifying enzyme $N$-deacetylase-N-sulfotransferase-1 deficiency exhibited significantly reduced acute rejection, along with altered HS and chondroitin sulfate disaccharide content. Celie et $\mathrm{al}^{83}$ also studied the relevance of microvascular basement membrane HSPGs to endothelial damage also in experimental renal $\mathrm{I} / \mathrm{R}$ and in human renal allograft biopsy samples. They found that the loss of endothelial expression of the extracellular endosulfatase human sulfatase 1 may be a likely mechanism 


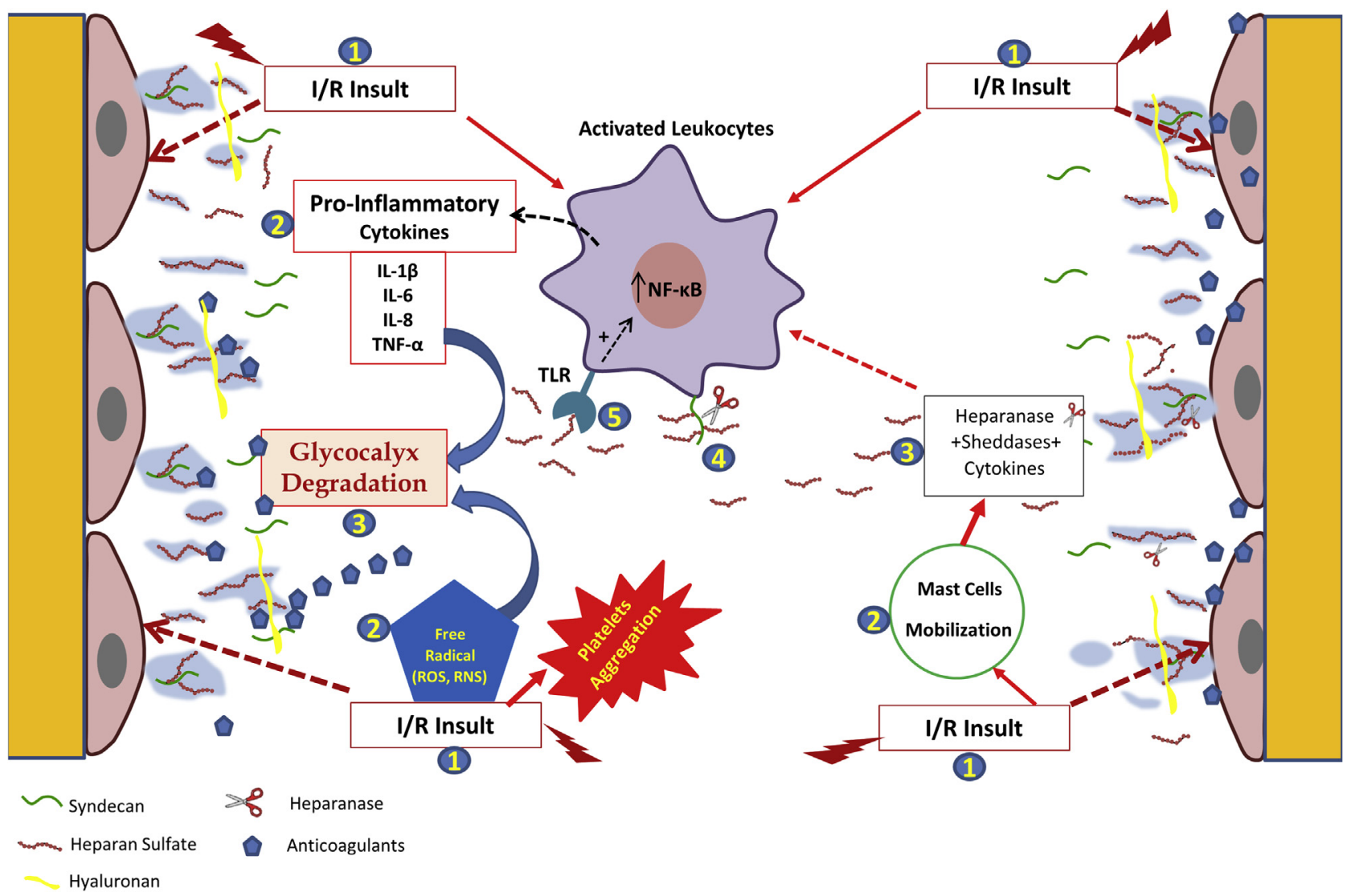

Figure 3 Interplay between I/R, the inflammatory, free radicals, platelet aggregation, and hemostasis systems. I/R (1) induces the production of reactive oxygen species (ROS)/reactive nitrogen species (RNS) by endothelial cells (ECS) and leukocytes (2) and the release of heparanase and other sheddases by ECs, platelets, and mast cells, leading to glycocalyx degradation (3). The degradation of HS yields circulating HS fragments (4), which activate the macrophages via immune receptors as evident by release of various pro-inflammatory cytokines, which in turn aggravate the glycocalyx damage (5). The glycocalyx also harbors anticoagulants such as antithrombin III and tissue factor pathway inhibitor, which prevent leukocyte and platelet adherence to ECs. In addition, the glycocalyx includes antioxidants such as superoxide dismutase (SOD) and xanthine oxidase into the circulation, rendering endothelial cells susceptible to further damage by ROS locally. Upon the degradation of glycocalyx, these anticoagulant and antioxidant substances are released, thus provoking coagulation and oxidative injury, respectively. TNF, tumor necrosis factor; TLR, Toll-like receptor.

underlying the induction of L-selectin- and monocyte chemoattractant protein 1-binding HSPGs associated with peritubular capillaries in human renal allograft rejection. In an additional clinical study in transplant recipients, a significant correlation was found between urinary heparanase and plasma levels of this enzyme. Interestingly, an inverse relationship was documented between urinary heparanase and estimated glomerular filtration rate, suggesting a deleterious role of this enzyme in kidney damage. ${ }^{84}$ Collectively, these findings put forward heparanase/HS as a novel biomarker of acute cellular rejection in solid organ transplantation. Moreover, the association between heparanase, proteinuria, and decreased renal function could be translated into new therapeutic options aimed at attenuating chronic renal allograft nephropathy, leading to improved graft survival and patients' outcomes.

As with renal allografts, it has been reported that the breakdown of EG occurs in lung transplant donors and recipients and predicts organ acceptability and the development of primary graft dysfunction, both in experimental settings as well as in clinical studies. ${ }^{85}$ Specifically, high donor SYND-1 levels were associated with primary graft dysfunction in recipients at 72 hours after transplantation. Complementing findings were obtained in pigs that were subjected to lung autotransplantation. As expected, ischemia caused pulmonary edema, which was greater after reperfusion, accompanied by decreased levels of SYND-1 and HS in lung tissues, along with increased levels of both glycocalyx components in plasma samples. ${ }^{14}$

Liver transplantation has been associated with profound hemostatic changes and bleeding due to depletions in coagulation factors and platelets. It often starts upon reperfusion with hyperfibrinolysis, which can eventually precipitate complete consumption of fibrinogen. Bleeding diathesis may further reflect an endogenous heparinization by glycocalyx shedding. ${ }^{86}$ It is noteworthy that glycocalyx degradation has been reported at baseline in patients with end-stage liver disease, ${ }^{14}$ and $\mathrm{I} / \mathrm{R}$ injury during orthotopic liver transplantation further exacerbates this damage, as evident by increased plasma SYND-1 levels. 
Collectively, ample evidence indicates glycocalyx breakdown after organ transplantation, and its degradation products may be useful biomarkers of tissue damage. Since glycocalyx breakdown further deteriorates microcirculation and oxygenation in transplanted organs, interventions to protect the glycocalyx conceivably might improve transplant outcomes.

\section{Mechanisms Underlying I/R-Induced Glycocalyx Damage}

\section{0xidative Stress}

As outlined in detail previously, ${ }^{5,87}$ injury to the glycocalyx in I/R is largely mediated by ROS, specifically through the activation of endothelial NADPH oxidase 2 and xanthine oxidase that are bound to glycosaminoglycans anchored at the endothelial surface layer (Figure 3). Furthermore, the release of ROS from leukocytes adherent to endothelial cells with damaged glycocalyx, as well as the release of glycocalyx-bound extracellular superoxide dismutase and xanthine oxidase into the circulation, render endothelial cells susceptible to further damage by ROS locally, or even provoking remote organ injury. ${ }^{12,88}$ Myeloperoxidase, released from neutrophils adhering to the injured endothelium, binds to the highly anionic glycocalyx, exposing adhesion molecules that promote homing of inflammatory cells and further intensify the breakdown of glycocalyx by cleaving the core glycocalyx protein SYND- $1 .{ }^{89}$ In addition, activated neutrophils induce the generation of reactive nitrogen species in the presence of nitric oxide, which, along with the release of granules containing proteases, aggravates glycocalyx degradation. ${ }^{73}$ Likewise, mobilized mast cells during I/R secrete heparanase, which cleaves HS side chains from membrane-bound core proteoglycans. ${ }^{27}$ In this context, HS cleavage induced by oxidative stress enhances the permeability of glycocalyx to macromolecules in a pattern similar to that observed after heparanase treatment. ${ }^{27,90}$ Furthermore, ROS and reactive nitrogen species are also known to activate matrix metalloproteinases and to stall endogenous protease inhibitors, thus facilitating glycocalyx degradation ${ }^{73,91}$ (Figure 3).

Solid evidence of the involvement of ROS in the pathogenesis of I/R-induced glycocalyx injury is derived from the unambiguous findings that inhibition of the oxygen radical-producing enzyme xanthine oxidoreductase or its removal largely preserves the glycocalyx and maintains its barrier properties. ${ }^{72}$ In this context, Rubio-Gayosso et $\mathrm{al}^{72}$ studied the impact of ROS on glycocalyx degradation using a model of mouse cremaster microvessels subjected to $\mathrm{I} / \mathrm{R}$ with enhanced permeability to $70-\mathrm{kDa}$ anionic dextran. This effect was ameliorated by the addition of exogenous superoxide dismutase-catalase, or the addition of either allopurinol or heparin. It should be emphasized that allopurinol exerts an antioxidant role on face of xanthine oxidoreductase, while heparin provokes competitive dissociation of xanthine oxidoreductase from the glycocalyx, thus preventing I/R-induced loss of glycocalyx barrier properties. In sum, disruption of the glycocalyx integrity during $I / R$ injury involves increased oxidative stress, secondary inflammatory response, and microvascular endothelial dysfunction, ${ }^{92}$ emphasizing the importance of interplay between oxidative stress and the inflammatory response in the pathogenesis of glycocalyx derangement characterizing ischemic injury.

\section{Heparan Sulfate and Heparanase}

HSPGs exert structural, biochemical, and regulatory functions in all body tissues. ${ }^{93}$ The most well-known components of HSPGs is HS, a chain of repeating disaccharide $\beta 1-4$-linked D-glucuronic acid and $\alpha_{1-4}$-linked $N$-acetyl-Dglucosamine, which is covalently attached to proteoglycans, mainly SYND-1 and -4 and glypican- $1 .^{93}$ An additional essential component of HSPGs is HA, a polymer containing repeats of disaccharides D-glucuronic acid and $N$-acetyl-Dglucosamine, linked by alternating $\beta_{1-4}$ and $\beta_{1-3}$ glycosidic bonds. ${ }^{93}$ Heparanase is an endoglycosidase that cleaves HS side chains of HSPGs into fragments of 10 to 20 sugar units, ${ }^{94}$ activity that is profoundly implicated in inflammation and cancer metastasis. ${ }^{49,95}$ However, several studies have implicated HS/heparanase also in the pathogenesis of $\mathrm{I} / \mathrm{R}$ in various clinical settings. For instance, the expression of SYND-1, a transmembrane HSPG, SYND-1 sheddases (a disintegrin and metalloprotease domain 17, matrix metalloproteinase 9) and heparanase were all significantly upregulated after renal transplantation. ${ }^{75}$ By using an I/R model in mice mutated for basement membrane HSPGs perlecan $\left(\mathrm{Hspg} 2^{\delta 3 / \delta 3}\right)$, collagen type XVIII $\left(\mathrm{Col} 18 \mathrm{a}^{-/-}\right)$, or both, Celie et $\mathrm{al}^{83}$ found that early monocyte/macrophage influx was impaired in $\mathrm{Hspg} 2^{\delta 3 / \delta 3} \times \mathrm{Col18}^{\mathrm{a} 1^{-1-}}$ mice. In the $\mathrm{I} / \mathrm{R}$ mice, monocyte chemotactic protein 1 binding was found to be similar to that in wild-type mice. Together, these data indicate that although L-selectin and monocyte chemotactic protein 1 binding to microvascular basement membrane HSPGs is induced in renal $\mathrm{I} / \mathrm{R}$, this binding is not exclusively mediated by either perlecan HS or collagen type XVIII. These findings were confirmed in human renal allograft biopsy samples, in which a loss of endothelial expression of the extracellular endosulfatase human sulfatase 1 may be involved in the induction of L-selectin- and monocyte chemoattractant protein 1-binding HSPGs associated with peritubular capillaries in human renal allograft rejection. In addition, we have demonstrated that renal I/R induced kidney dysfunction and adverse histologic alterations, which were more profound in heparanase overexpressing transgenic (Hpa-Tg) mice compared to wild-type animals. ${ }^{31,80}$ Moreover, the hypersensitivity of the renal tissue to I/R in Hpa-Tg mice was associated with activation of the NF- $\kappa$ B pathway. ${ }^{31}$ It is highly suggestive that heparanase is involved in the degradation of EG during I/R, similar to the situation in sepsis, in which concomitant activation of the NF- $\mathrm{KB}$ pathway and heparanases (I and III) and other sheddases (a disintegrin and metalloprotease 
Table 1 Pharmacologic or Nonpharmacologic Therapeutics for Preventing Ischemic Endothelial Glycocalyx Injury or Restoration of Its Ultrastructure

\begin{tabular}{|c|c|c|}
\hline Therapy & Dose, route of administration & Model \\
\hline $\mathrm{SOD}^{104}$ & $150 \mathrm{U} / \mathrm{mL}$ perfusate & $\begin{array}{l}\text { Langendorff-perfused guinea } \\
\text { pig hearts subjected to } 30 \\
\text { minutes ischemia/35 } \\
\text { minutes reperfusion }\end{array}$ \\
\hline Sevoflurane ${ }^{19}$ & $(2 \% \mathrm{v} / \mathrm{v})$ inhalation & $\begin{array}{l}\text { Hepatic I/R ( } 45 \text { minutes) } \\
\text { injury in Sprague Dawley } \\
\text { rats }\end{array}$ \\
\hline $\begin{array}{l}\text { Superoxide dismutase-catalase } \\
\text { Allopurinol heparin } \\
\text { hyaluronan }^{72}\end{array}$ & $\begin{array}{l}50 \text { units of SOD and } 50 \text { units } \\
\text { of catalase }(\mathrm{SOD} / \text { Cat) } \\
0.5,2.5, \text { or } 5 \mathrm{mg} / \mathrm{kg} \text { heparin } \\
(300 \mathrm{U} / \mathrm{kg}) \\
(80 \mu \mathrm{g} \text { each) }\end{array}$ & $\begin{array}{l}\text { In vitro } \mathrm{I} / \mathrm{R} \text { injury ( } 45 \\
\text { minutes) in mouse } \\
\text { cremasteric microvessels }\end{array}$ \\
\hline $\begin{array}{l}\text {-(2-mercaptopropionyl)- } \\
\text { glycine, an } 0 \mathrm{H} \text { radical } \\
\text { scavenger }^{105}\end{array}$ & Pretreatment with $5 \mathrm{mmol} / \mathrm{L}$ & $\begin{array}{l}\text { Isolated working rat hearts } \\
\text { subjected to } 20 \text { minutes of } \\
\text { ischemia followed by } 3 \text { or } \\
30 \text { minutes of reperfusion }\end{array}$ \\
\hline $\mathrm{NO}^{6}$ & $4 \mu \mathrm{mol} / \mathrm{L} \mathrm{NO}$ & $\begin{array}{l}\text { Isolated working hearts } \\
\text { subjected to } 15 \text { minutes of } \\
\text { ischemia followed by } 20 \\
\text { minutes of reperfusion }\end{array}$ \\
\hline Antithrombin ${ }^{106}$ & $\begin{array}{l}\text { Infusion with Krebs-Henseleit } \\
\text { buffer including } \\
\text { antithrombin }(1 \mathrm{U} / \mathrm{mL})\end{array}$ & $\begin{array}{l}\text { Ischemia (20 minutes)/ } \\
\text { reperfusion ( } 20 \text { minutes) in } \\
\text { isolated guinea pig hearts }\end{array}$ \\
\hline Antithrombin ${ }^{78}$ & $\begin{array}{l}\text { Infusion with Krebs-Henseleit } \\
\text { buffer including } \\
\text { antithrombin }(1 \mathrm{U} / \mathrm{mL})\end{array}$ & $\begin{array}{l}\text { Ischemia (20 minutes)/ } \\
\text { reperfusion (10 minutes) in } \\
\text { isolated guinea pig hearts }\end{array}$ \\
\hline
\end{tabular}

Protection of glycocalyx disruption and improvement of its ultrastructure

Reduced shedding of HS and glycocalyx damage assessed by electron microscopy in the presence of NO

Preservation of the endothelial glycocalyx, sustaining the vascular barrier function and reducing interstitial edema

Intact coronary glycocalyx after antithrombin pretreatment; preservation of the glycocalyx, mitigating postischemic polymorphonuclear neutrophilic cell adhesion

Hydrocortisone ${ }^{107}$

Sevoflurane ${ }^{18}$

Sevoflurane ${ }^{108}$

Sevoflurane ${ }^{109}$
15 minutes at $2 \% \mathrm{v} / \mathrm{v}$ gas

$10 \mu \mathrm{g} / \mathrm{mL}$ before inducing 20 minutes of ischemia

0.5 or 1 minimal alveolar concentration sevoflurane

1 minimum alveolar concentration sevoflurane
$I / R$ in isolated guinea pig hearts

Ischemia (20 minutes)/ reperfusion (10 minutes) in isolated guinea pig hearts

Ischemia (20 minutes)/ reperfusion in isolated guinea pig hearts

Ischemia (20 minutes)/ reperfusion (40 minutes) in isolated guinea pig hearts

Ischemia (90 minutes)/ reperfusion (120 minutes) in pig heart with balloon

Sevoflurane ${ }^{110}$
Inhaled at $0.5-1$ vol\% endtidal concentrations
15 minutes of forearm ischemia in healthy volunteers in the presence or absence of sevoflurane
Reduction of glycocalyx shedding (reducing SYND1 , HS, and hyaluronan release)

Reduction of glycocalyx shedding (reduction of HS and SYND-1 release)

Attenuation of SYND-1 and $\mathrm{HS}$ release from coronary arteries

Inhibition of glycosaminoglycan hyaluronan shedding and preservation of $\mathrm{HS}$ and SYND-1

Protection of the endothelium from IR injury as evident by attenuated HS release

Improvement of postocclusive hyperemic reaction 
Table 1 (continued)

\begin{tabular}{|c|c|c|c|}
\hline Therapy & Dose, route of administration & Model & Major finding \\
\hline $\begin{array}{l}\text { Hyaluronan and chondroitin } \\
\text { sulfate }^{111}\end{array}$ & $\begin{array}{l}\text { IV bolus of } 24 \mathrm{mg} \text { followed by } \\
0.4 \mathrm{mg} / \mathrm{mL} \text { at a rate of } 0.49 \\
\mathrm{~mL} / \text { hour after } 1 \text { hour of } \\
\text { vascular insult }\end{array}$ & $\begin{array}{l}\text { Hamster microvessels in the } \\
\text { cremaster muscle } \\
\text { pretreated with } \\
\text { hyaluronidase }\end{array}$ & $\begin{array}{l}\text { Reconstitution of the } \\
\text { glycocalyx }\end{array}$ \\
\hline Albumin ${ }^{112}$ & $\begin{array}{l}\text { Infusion with Krebs-Henseleit } \\
\text { buffer augmented with } \\
\text { colloids (one-third volume } \\
5 \% \text { albumin) }\end{array}$ & $\begin{array}{l}\text { Ischemia ( } 20 \text { minutes)/ } \\
\text { reperfusion in isolated } \\
\text { guinea pig hearts }\end{array}$ & $\begin{array}{l}\text { Prevention of fluid } \\
\text { extravasation in the heart, } \\
\text { along with preservation of } \\
\text { endothelial glycocalyx }\end{array}$ \\
\hline Albumin ${ }^{113}$ & $\begin{array}{l}\text { Preservation of isolated heart } \\
\text { for } 4 \text { hours in } \\
\text { Bretschneider's solution } \\
\text { without and with } \\
\text { augmentation with } 1 \mathrm{~g} \% \\
\text { human albumin }\end{array}$ & $\begin{array}{l}\text { Cold ischemia in guinea pig } \\
\text { hearts for } 4 \text { hours }\end{array}$ & $\begin{array}{l}\text { Glycocalyx shedding } \\
\text { significantly reduced when } \\
\text { albumin added to storage } \\
\text { solution }\end{array}$ \\
\hline Sulodexide ${ }^{115}$ & $\begin{array}{l}0.5 \mathrm{mg} / \mathrm{kg} \text { administered at } \\
\text { the end of regional } \\
\text { ischemia and at each hour } \\
\text { of reperfusion }\end{array}$ & $\begin{array}{l}\text { ischemic myocardium in } \\
\text { anesthetized rabbits } \\
\text { underwent } 30 \text { minutes of } \\
\text { coronary artery occlusion }\end{array}$ & $\begin{array}{l}\text { Sulodexide reduced infarct } \\
\text { size, and troponin I levels }\end{array}$ \\
\hline
\end{tabular}

HS, heparan sulfate; I/R, ischemia-reperfusion; N0, nitric oxide; PBS, phosphate-buffered saline; PMN, polymorphonuclear neutrophilic cell; SYND, syndecan; SOD, superoxide dismutase.

domain-17) was observed. ${ }^{96}$ However, not all studies that have explored the involvement of heparanase in the pathogenesis of I/R-induced tissue injury have demonstrated deleterious impact. For example, Wang et $\mathrm{al}^{97}$ demonstrated that overexpression of heparanase can defend the heart against chemically induced or I/R injury, as evident by lower infarct size and attenuated markers of apoptosis in the Hep-Tg heart compared to wild type. ${ }^{97}$ These findings are in agreement with those from previous studies that established a protective function of heparanase in the acutely diabetic heart, in which it conferred cardiomyocyte resistance to oxidative stress and apoptosis by provoking changes in gene expression. ${ }^{98}$ In line with these findings, unfolding protein response and autophagy inhibitors have been reported to reduce the protective effects of heparanase overexpression during $I / R$, suggesting that heparanase promotes cell survival by providing protection against cellular stresses, and consequently prevents glycocalyx detachment. ${ }^{97}$ The observed unfolding protein response activation in I/R Hpa$\mathrm{Tg}$ mice was adaptive and not apoptotic, mediated by the activation of activating transcription factor $6 \alpha$ and, when combined with mammalian target of rapamycin inhibition, induced autophagy. In contrast, inducing cardiac $\mathrm{I} / \mathrm{R}$ in wild-type mice induced endoplasmic reticulum stress and evoked a transition from an adaptive to an apoptotic unfolding protein response, an effect that was attenuated in Hep-Tg mouse hearts. ${ }^{97}$

In light of the findings from an overwhelming majority of studies, Zhang et $\mathrm{al}^{4}$ recently outlined a feed-forward loop of altered glycocalyx and endothelial dysfunction, underlining the need for glycocalyx protection and repair to improve tissue survival under conditions characterized by endothelial dysfunction, such as I/R (Restoration of Glycocalyx as a Therapeutic Approach in I/R Injury).

\section{Techniques Utilized for Measurement of Glycocalyx}

In light of the substantial difficulties in measuring EG in the clinical setting, which involves special electron microscopy fixation/preservation of the tissue, that in turn requires preperfusion with different dyes, which is not practical for biopsy material, novel techniques for the measurement of glycocalyx thickness have been developed. At the clinical level, there are two known methods of determining glycocalyx thickness: i) indirect visualization of the glycocalyx, and ii) determination of its degradation products in the circulation. ${ }^{99}$ Indirect visualization utilizes in vivo video microscopy techniques, such as sidestream dark field imaging in conjunction with software, ${ }^{100}$ allowing indirect assessment of EG thickness in sublingual microcirculation by measuring the penetration extent (referred to as the 
perfused boundary region) of flowing red blood cells into the EG. This technique is applied mainly to explore changes in glycocalyx thickness in the sublingual mucosa, which assumedly reflects the status of the whole-body vasculature. ${ }^{99}$ For instance, a significant increase in the perfused boundary region was obtained in both neurocritical and nonseptic patients in the intensive care unit after cardiac surgery, compared to controls. Furthermore, the reduced sublingual glycocalyx thickness was associated with enhanced circulatory SYND-1, a biomarker of glycocalyx degradation. ${ }^{100}$ Recently, a novel handheld microscope based on incident dark field illumination was introduced for clinical use. The CytoCam incident dark field illumination imaging device (Braedius Medical, Huizen, the Netherlands) consists of a pen-like probe incorporating incident dark field illumination with a set of high-resolution lenses that project images onto a computer-controlled image sensor synchronized with very short-pulsed illumination light. This method seems more reliable than sidestream dark field imaging for the clinical assessment of microcirculatory alterations. ${ }^{101}$ However, it is uncertain whether the alterations in the sublingual small vessels reflects the microvasculature in other organs such as kidney, heart, lung, liver, and brain. Yet, a recent study from Haeren et $\mathrm{al}^{102}$ reported that sidestream dark field imaging of sublingual, cortical, and hippocampal microcirculation glycocalyx in patients revealed similar patterns at all three measurement sites.

Similar to human studies, experimental research has applied laboratory methods to assess the amount of EG damage, including measuring circulatory levels of its degradation products (eg, SYND-1, HS, and hyaluronan sulfate). ${ }^{103}$ In vivo video microscopy technologies, such as sidestream dark field, have also been applied in animal research. However, electron microscopy fixation/preservation of the tissue requires preperfusion with different dyes, which is not practical for biopsy material and is more feasible in animal studies.

\section{Restoration of Glycocalyx as a Therapeutic Approach in I/R Injury}

In light of the widely accepted notion that $\mathrm{I} / \mathrm{R}$ is characterized by glycocalyx damage, several pharmacologic or nonpharmacologic therapeutic interventions have been tested, aimed at either preventing glycocalyx injury or restoring the ultrastructure of the surface layer of endothelial cells (Table 1). ${ }^{11,13,18-20,61,104-116}$ The most attractive maneuver utilizes i.v. administration of core components of endothelial glycocalyx or relies on inhibiting the enzymes involved in its degradation in various pathological conditions. ${ }^{11,13,18-20,61,104-116}$ Studying the coronary vascular system of isolated guinea pig hearts, Chappel et $\mathrm{al}^{107}$ found that none of a host of interventions, including tryptase, elastase, proteinase-3, thrombin, tissue-type plasminogen activator, plasmin, and cathepsin $\mathrm{B}$, caused a significant elevation in coronary washout of SYND-1, suggesting a minor role of these enzymes in glycocalyx shedding. However, both cathepsin B and elastase induced a slight increase in HS release. Similarly, cathepsin B, thrombin, elastase, plasmin, and proteinase- 3 provoked a slight washout of hyaluronan. ${ }^{107}$ These findings partially support the reports that these sheddases are involved in inflammatory reactions during $\mathrm{I} / \mathrm{R}^{117}$ and that antithrombin exerts a protective effect against glycocalyx shedding in experimental ischemic and inflammatory conditions. ${ }^{57,78,106}$ Heparanase is an additional enzyme that most likely plays an essential role in cleaving glycocalyx and components of the extracellular matrix. Heparanase degrades HS, an integral part of glycocalyx and extracellular matrix, which harbor distinct growth factors, cytokines, and other biologically active molecules, as well as side chains of cell surface proteins, including syndecans and glypicans. ${ }^{48,118}$ Moreover, heparanase is up-regulated in the renal tissue during I/ R-induced $\mathrm{AKI},{ }^{31,80}$ as well as in sepsis-induced renal injury. ${ }^{119}$ These observations led us to explore the impact of heparanase inhibition in a rodent model of ischemic AKI, produced by protracted clamping of the renal artery with subsequent reperfusion. Indeed, PG545, a potent heparanase inhibitor, alleviated tubular damage and attenuated the elevation in serum creatinine and blood urea nitrogen in wild-type mice and especially in Hpa-Tg mice. ${ }^{31,80}$ Moreover, transforming growth factor $\beta$, vimentin, fibronectin, and $\alpha$-smooth muscle actin, biomarkers of fibrosis, as well as TNF- $\alpha$, Il-6, and endothelin-1, biomarkers of inflammation, were up-regulated in I/R-induced AKI, primarily in Hpa-Tg mice, suggesting an adverse role of heparanase in the pathogenesis of AKI. Remarkably, pretreatment of mice with PG545 ameliorated kidney dysfunction and attenuated the up-regulation of heparanase and proinflammatory (ie, Il6 ) and profibrotic (ie, transforming growth factor $\beta$ ) genes induced by $I / R$. This warm $I / R$ model is highly reproducible and enables the assessment of both tissue integrity and kidney function, and pathophysiologically closely parallels that of the clinically relevant cardiac I/R injury, or in the setting of kidney transplantation. Yet, as outlined in Renal I/ $R$ Injury, it does not represent the common setting of hypoxic kidney injury in clinical practice, in which total cessation of renal blood flow rarely occurs. However, evidence of endothelial damage has seldom been encountered after profound and protracted hypotension, ${ }^{3,30}$ and similar findings with heparanase were reported in AKI induced by polymicrobial sepsis in mice using cecal ligation and puncture. ${ }^{119}$ The devolvement of kidney dysfunction was associated with enhanced heparanase activity along with HS loss. Interestingly, the administration of heparin or nonanticoagulant $N$-desulfated re- $N$-acetylated heparin 2 hours before cecal ligation and puncture attenuated the deleterious renal consequences of sepsis, suggesting that glomerular heparanase is activated during sepsis and contributes to septic renal dysfunction, likely via glycocalyx shedding.

Protection of glycocalyx is also evident by the administration of antithrombin III after cardiac arrest syndrome, in 
which generalized I/R takes place, ${ }^{54}$ and after hydrocortisone treatment in ischemic cardiac insult induced by TNF$\alpha,{ }^{57,78,107}$ with both treatments reducing glycocalyx shedding and leukocyte adhesion. Protection of glycocalyx could also be achieved by the infusion of albumin, as it binds to the endothelial surface and shields it from enzymatic attack as antithrombin III may do. Moreover, albuminenriched glycocalyx serves as an anti-acid buffer and ROS scavenger and impairs the adhesion of leukocytes to the vascular wall, thus reducing inflammation and increased permeability of water and colloids to the interstitium. Promising protective effect against glycocalyx shedding has also been obtained with sevoflurane, an anesthetic agent, in various experimental settings, ${ }^{18,108}$ including ex vivo cardiac $\mathrm{I} / \mathrm{R},{ }^{109}$ hepatic I/R injury, ${ }^{19}$ and I/R-induced lung injury, ${ }^{13}$ Interestingly, pretreatment with sevoflurane protected pulmonary glycocalyx and reduced the expression of leukocyte chemokines in a pulmonary autotransplantation model. ${ }^{13}$ These results support the use of this anesthetic gas in surgical procedures due to its antioxidant properties and glycocalyx-protective activity.

An additional approach to the restoration of glycocalyx integrity relies on the i.v. administration of core components of the glycocalyx. Using an in vitro system of cremaster blood vessels, Rubio-Gayosso et al $^{72}$ reported that glycocalyx damage induced by $\mathrm{I} / \mathrm{R}$ could be partially prevented or fully reversed with the intravascular infusion of exogenous hyaluronan, either before the ischemic insult or shortly after it, respectively. In vivo, oral administration of sulodexide, a mixture of natural porcine heparan and dermatan sulfates, yielded beneficial effects in various cardiovascular diseases (chronic venous disease and arterial diseases) and renal diseases, including diabetic nephropathy. ${ }^{120-122}$ In fact, sulodexide therapy for 2 weeks up to 12 months was reported to reduce proteinuria, ${ }^{123}$ along with the attenuation of EG degradation, in diabetic patients. The beneficial effects of sulodexide are attributed to its ability to convert to $\mathrm{N}$ acetyl-glucosamine, which serves as a precursor to glycosaminoglycans in the EG. ${ }^{124}$ A similar stabilizing effect on EG was achieved by the administration of albumin carrying sphingosin-1 phosphate to endothelial cells derived from rat fat-pad, likely by reducing the shedding of glycosaminoglycans. ${ }^{125}$ It has been proposed that sulodexide possesses direct effects against HS degradation. ${ }^{123}$ However, in contrast to the initially encouraging results, a larger-scale blinded study failed to reproduce the nephroprotective effects of sulodexide in patients with diabetic nephropathy. ${ }^{126}$

Most recently, novel liposomal nanocarriers of preassembled glycocalyx were introduced to expeditiously mend degraded EG. ${ }^{4}$ In a pilot study, SYND-1 was incorporated into liposomes, reacting with HS and intertwining hyaluronic acid chains. Functional testing of liposomal carriers of the preassembled glycocalyx revealed that they potently and quickly improved mechanoactivation-induced nitric oxide generation in cultured endothelial cells pretreated with heparanase III, and showed restoration of vascular permeability after treatment with liposomal nanocarriers of preassembled glycocalyx. Though these are exciting preliminary findings, the efficacy of liposomal nanocarriers in promoting normal vascular reactivity after $\mathrm{I} / \mathrm{R}$ insult requires further evaluation.

\section{Summary and Future Perspectives}

Glycocalyx plays a pivotal role in the regulation of endothelial function, including vascular permeability, mechanotransduction, and hemostasis. This bushy layer is damaged in various disease states such as sepsis, regional or global I/ $\mathrm{R}$, major surgery, oxidative stress, hyperglycemia, hypervolemia, and organ transplantation. The deleterious impact of these pathophysiologies is evident by elevated plasma levels of glycocalyx components, that is, SYND-1 and HS, along with the thinning of glycocalyx and eventually the development of endothelial dysfunction. Therefore, protection and restoration of the microscopic structure and function of the glycocalyx comprises a promising therapeutic approach in various clinical settings including ischemic organ injuries, a common finding in major surgeries and organ transplantations. Moreover, circulatory levels of SYND-1 and HS, along with other glycocalyx ingredients, could be used as valid biomarkers to monitor the severity of vascular endothelial damage and to confirm successful protective interventions in certain $\mathrm{I} / \mathrm{R}$ settings. However, there is still a long way to go in tracking down the precise source of rising plasma levels of SYND-1 and HS, their pharmacokinetics, and the best approach to restoring glycocalyx integrity by pharmacologic and nonpharmacologic maneuvers.

\section{References}

1. Kalogeris T, Baines CP, Krenz M, Korthuis RJ: Cell biology of ischemia/reperfusion injury. Int Rev Cell Mol Biol 2012, 298: 229-317

2. Kalogeris T, Baines CP, Krenz M, Korthuis RJ: Ischemia/reperfusion. Compr Physiol 2016, 7:113-170

3. Abassi Z, Rosen S, Lamothe S, Heyman SN: Why have detection, understanding and management of kidney hypoxic injury lagged behind those for the heart? J Clin Med 2019, 8:267

4. Zhang X, Sun D, Song JW, Zullo J, Lipphardt M, Coneh-Gould L, Goligorsky MS: Endothelial cell dysfunction and glycocalyx - a vicious circle. Matrix Biol 2018, 71-72:421-431

5. Yu H, Kalogeris T, Korthuis RJ: Reactive species-induced microvascular dysfunction in ischemia/reperfusion. Free Radic Biol Med 2019, 135:182-197

6. Bruegger D, Rehm M, Jacob M, Chappell D, Stoeckelhuber M, Welsch U, Conzen P, Becker BF: Exogenous nitric oxide requires an endothelial glycocalyx to prevent postischemic coronary vascular leak in guinea pig hearts. Crit Care 2008, 12:R73

7. Lee SJ, Lee CK, Kang S, Park I, Kim YH, Kim SK, Hong SP, Bae H, He Y, Kubota Y, Koh GY: Angiopoietin-2 exacerbates cardiac hypoxia and inflammation after myocardial infarction. J Clin Invest 2018, 128:5018-5033

8. Bruegger D, Brettner F, Rossberg I, Nussbaum C, Kowalski C, Januszewska K, Becker BF, Chappell D: Acute degradation of the 
endothelial glycocalyx in infants undergoing cardiac surgical procedures. Ann Thorac Surg 2015, 99:926-931

9. Bruegger D, Rehm M, Abicht J, Paul JO, Stoeckelhuber M, Pfirrmann M, Reichart B, Becker BF, Christ F: Shedding of the endothelial glycocalyx during cardiac surgery: on-pump versus offpump coronary artery bypass graft surgery. J Thorac Cardiovasc Surg 2009, 138:1445-1447

10. Rehm M, Bruegger D, Christ F, Conzen P, Thiel M, Jacob M, Chappell D, Stoeckelhuber M, Welsch U, Reichart B, Peter K, Becker BF: Shedding of the endothelial glycocalyx in patients undergoing major vascular surgery with global and regional ischemia. Circulation 2007, 116:1896-1906

11. Annecke T, Rehm M, Bruegger D, Kubitz JC, Kemming GI, Stoeckelhuber M, Becker BF, Conzen PF: Ischemia-reperfusioninduced unmeasured anion generation and glycocalyx shedding: sevoflurane versus propofol anesthesia. J Invest Surg 2012, 25: $162-168$

12. van Golen RF, Reiniers MJ, Vrisekoop N, Zuurbier CJ, Olthof PB, van Rheenen J, van Gulik TM, Parsons BJ, Heger M: The mechanisms and physiological relevance of glycocalyx degradation in hepatic ischemia/reperfusion injury. Antioxid Redox Signal 2014, 21: $1098-1118$

13. Casanova J, Simon C, Vara E, Sanchez G, Rancan L, Abubakra S, Calvo A, Gonzalez FJ, Garutti I: Sevoflurane anesthetic preconditioning protects the lung endothelial glycocalyx from ischemia reperfusion injury in an experimental lung autotransplant model. J Anesth 2016, 30:755-762

14. Rancan L, Simon C, Sanchez Pedrosa G, Aymonnier K, Shahani PM, Casanova J, Munoz C, Garutti I, Vara E: Glycocalyx degradation after pulmonary transplantation surgery. Eur Surg Res 2018, 59: $115-125$

15. Schiefer J, Lebherz-Eichinger D, Erdoes G, Berlakovich G, Bacher A, Krenn CG, Faybik P: Alterations of endothelial glycocalyx during orthotopic liver transplantation in patients with end-stage liver disease. Transplantation 2015, 99:2118-2123

16. Snoeijs MG, Vink H, Voesten N, Christiaans MH, Daemen JW, Peppelenbosch AG, Tordoir JH, Peutz-Kootstra CJ, Buurman WA, Schurink GW, van Heurn LW: Acute ischemic injury to the renal microvasculature in human kidney transplantation. Am J Physiol Renal Physiol 2010, 299:F1134-F1140

17. Chappell D, Brettner F, Doerfler N, Jacob M, Rehm M, Bruegger D, Conzen P, Jacob B, Becker BF: Protection of glycocalyx decreases platelet adhesion after ischaemia/reperfusion: an animal study. Eur J Anaesthesiol 2014, 31:474-481

18. Chappell D, Heindl B, Jacob M, Annecke T, Chen C, Rehm M, Conzen P, Becker BF: Sevoflurane reduces leukocyte and platelet adhesion after ischemia-reperfusion by protecting the endothelial glycocalyx. Anesthesiology 2011, 115:483-491

19. Li J, Yuan T, Zhao X, Lv GY, Liu HQ: Protective effects of sevoflurane in hepatic ischemia-reperfusion injury. Int J Immunopathol Pharmacol 2016, 29:300-307

20. Oller L, Dyer WB, Santamaria L, Largo C, Javidroozi M, Shander A: The effect of a novel intravenous fluid (Oxsealife(R)) on recovery from haemorrhagic shock in pigs. Anaesthesia 2019, 74:765-777

21. Frydland M, Ostrowski SR, Moller JE, Hadziselimovic E, Holmvang L, Ravn HB, Jensen LO, Pettersson AS, Kjaergaard J, Lindholm MG, Johansson PI, Hassager C: Plasma concentration of biomarkers reflecting endothelial cell- and glycocalyx damage are increased in patients with suspected ST-elevation myocardial infarction complicated by cardiogenic shock. Shock 2018, 50:538-544

22. Naumann DN, Hazeldine J, Midwinter MJ, Hutchings SD, Harrison P: Poor microcirculatory flow dynamics are associated with endothelial cell damage and glycocalyx shedding after traumatic hemorrhagic shock. J Trauma Acute Care Surg 2018, 84:81-88

23. Kozar RA, Peng Z, Zhang R, Holcomb JB, Pati S, Park P, Ko TC, Paredes A: Plasma restoration of endothelial glycocalyx in a rodent model of hemorrhagic shock. Anesth Analg 2011, 112:1289-1295
24. Torres Filho I, Torres LN, Sondeen JL, Polykratis IA, Dubick MA: In vivo evaluation of venular glycocalyx during hemorrhagic shock in rats using intravital microscopy. Microvasc Res 2013, 85:128-133

25. Halbgebauer $R$, Braun $C K$, Denk $S$, Mayer $B$, Cinelli $P$, Radermacher P, Wanner GA, Simmen HP, Gebhard F, Rittirsch D, Huber-Lang M: Hemorrhagic shock drives glycocalyx, barrier and organ dysfunction early after polytrauma. J Crit Care 2018, 44: 229-237

26. Johansson PI, Stensballe J, Rasmussen LS, Ostrowski SR: A high admission syndecan-1 level, a marker of endothelial glycocalyx degradation, is associated with inflammation, protein $\mathrm{C}$ depletion, fibrinolysis, and increased mortality in trauma patients. Ann Surg 2011, 254:194-200

27. Song JW, Goligorsky MS: Perioperative implication of the endothelial glycocalyx. Korean J Anesthesiol 2018, 71:92-102

28. Goligorsky MS, Maizel J: Pathophysiology of acute kidney injury. Oxford Textbook of Clinical Nephrology, ed 4. Edited by Turner NN, Goldsmith DJ, Winearls CG, Himmelfarb J, Remuzzi G. Oxford: Oxford University Press, 2015. pp. 1844-1871

29. Brezis M, Rosen S: Hypoxia of the renal medulla-its implications for disease. N Engl J Med 1995, 332:647-655

30. Rosen S, Heyman SN: Difficulties in understanding human "acute tubular necrosis": limited data and flawed animal models. Kidney Int 2001, 60:1220-1224

31. Abassi Z, Hamoud S, Hassan A, Khamaysi I, Nativ O, Heyman SN, Muhammad RS, Ilan N, Singh P, Hammond E, Zaza G, Lupo A, Onisto M, Bellin G, Masola V, Vlodavsky I, Gambaro G: Involvement of heparanase in the pathogenesis of acute kidney injury: nephroprotective effect of PG545. Oncotarget 2017, 8:34191-34204

32. Song JW, Zullo JA, Liveris D, Dragovich M, Zhang XF, Goligorsky MS: Therapeutic restoration of endothelial glycocalyx in sepsis. J Pharmacol Exp Ther 2017, 361:115-121

33. Schley G, Cordasic N, Klanke B, Heyman S, Rosen S, Eckardt K, Willam C: Radiocontrast nephropathy: role of endothelial injury, and chronic consequences. ASN Meeting 2013:648

34. Basile DP, Yoder MC: Renal endothelial dysfunction in acute kidney ischemia reperfusion injury. Cardiovasc Hematol Disord Drug Targets 2014, 14:3-14

35. Jourde-Chiche N, Fakhouri F, Dou L, Bellien J, Burtey S, Frimat M, Jarrot PA, Kaplanski G, Le Quintrec M, Pernin V, Rigothier C, Sallee M, Fremeaux-Bacchi V, Guerrot D, Roumenina LT: Endothelium structure and function in kidney health and disease. Nat Rev Nephrol 2019, 15:87-108

36. Friden V, Oveland E, Tenstad O, Ebefors K, Nystrom J, Nilsson UA, Haraldsson B: The glomerular endothelial cell coat is essential for glomerular filtration. Kidney Int 2011, 79:1322-1330

37. Haraldsson B, Nystrom J, Deen WM: Properties of the glomerular barrier and mechanisms of proteinuria. Physiol Rev 2008, 88: 451-487

38. Jeansson M, Haraldsson B: Morphological and functional evidence for an important role of the endothelial cell glycocalyx in the glomerular barrier. Am J Physiol Renal Physiol 2006, 290:F111-F116

39. Salmon AH, Ferguson JK, Burford JL, Gevorgyan H, Nakano D, Harper SJ, Bates DO, Peti-Peterdi J: Loss of the endothelial glycocalyx links albuminuria and vascular dysfunction. J Am Soc Nephrol 2012, 23:1339-1350

40. Padberg JS, Wiesinger A, di Marco GS, Reuter S, Grabner A, Kentrup D, Lukasz A, Oberleithner H, Pavenstadt H, Brand M, Kumpers P: Damage of the endothelial glycocalyx in chronic kidney disease. Atherosclerosis 2014, 234:335-343

41. Singh A, Friden V, Dasgupta I, Foster RR, Welsh GI, Tooke JE, Haraldsson B, Mathieson PW, Satchell SC: High glucose causes dysfunction of the human glomerular endothelial glycocalyx. Am J Physiol Renal Physiol 2011, 300:F40-F48

42. Vlahu CA, Lemkes BA, Struijk DG, Koopman MG, Krediet RT, Vink H: Damage of the endothelial glycocalyx in dialysis patients. J Am Soc Nephrol 2012, 23:1900-1908 
43. Uchimido R, Schmidt EP, Shapiro NI: The glycocalyx: a novel diagnostic and therapeutic target in sepsis. Crit Care 2019, 23:16

44. Dane MJ, Khairoun M, Lee DH, van den Berg BM, Eskens BJ, Boels MG, van Teeffelen JW, Rops AL, van der Vlag J, van Zonneveld AJ, Reinders ME, Vink H, Rabelink TJ: Association of kidney function with changes in the endothelial surface layer. Clin J Am Soc Nephrol 2014, 9:698-704

45. Annecke T, Fischer J, Hartmann H, Tschoep J, Rehm M, Conzen P, Sommerhoff CP, Becker BF: Shedding of the coronary endothelial glycocalyx: effects of hypoxia/reoxygenation vs ischaemia/reperfusion. Br J Anaesth 2011, 107:679-686

46. Becker BF, Fischer J, Hartmann H, Chen CC, Sommerhoff CP, Tschoep J, Conzen PC, Annecke T: Inosine, not adenosine, initiates endothelial glycocalyx degradation in cardiac ischemia and hypoxia. Nucleosides Nucleotides Nucleic Acids 2011, 30:1161-1167

47. Takai S, Jin D: Improvement of cardiovascular remodelling by chymase inhibitor. Clin Exp Pharmacol Physiol 2016, 43:387-393

48. Chappell D, Jacob M, Rehm M, Stoeckelhuber M, Welsch U, Conzen P, Becker BF: Heparinase selectively sheds heparan sulphate from the endothelial glycocalyx. Biol Chem 2008, 389:79-82

49. Vlodavsky I, Iozzo RV, Sanderson RD: Heparanase: multiple functions in inflammation, diabetes and atherosclerosis. Matrix Biol 2013, $32: 220-222$

50. Svennevig K, Hoel TN, Thiara AS, Kolset SO, Castelheim A, Mollnes TE, Brosstad F, Fosse E, Svennevig JL: Syndecan-1 plasma levels during coronary artery bypass surgery with and without cardiopulmonary bypass. Perfusion 2008, 23:165-171

51. Massoudy P, Zahler S, Becker BF, Braun SL, Barankay A, Meisner H: Evidence for inflammatory responses of the lungs during coronary artery bypass grafting with cardiopulmonary bypass. Chest 2001, 119:31-36

52. Maksimenko AV, Turashev AD: No-reflow phenomenon and endothelial glycocalyx of microcirculation. Biochem Res Int 2012, 2012: 859231

53. Yamamoto T, Tada T, Brodsky SV, Tanaka H, Noiri E, Kajiya F, Goligorsky MS: Intravital videomicroscopy of peritubular capillaries in renal ischemia. Am J Physiol Renal Physiol 2002, 282: F1150-F1155

54. Grundmann S, Fink K, Rabadzhieva L, Bourgeois N, Schwab T, Moser M, Bode C, Busch HJ: Perturbation of the endothelial glycocalyx in post cardiac arrest syndrome. Resuscitation 2012, 83: $715-720$

55. Warren OJ, Smith AJ, Alexiou C, Rogers PL, Jawad N, Vincent C, Darzi AW, Athanasiou T: The inflammatory response to cardiopulmonary bypass: part 1-mechanisms of pathogenesis. J Cardiothorac Vasc Anesth 2009, 23:223-231

56. Aydin NB, Gercekoglu H, Aksu B, Ozkul V, Sener T, Kiygil I, Turkoglu T, Cimen S, Babacan F, Demirtas M: Endotoxemia in coronary artery bypass surgery: a comparison of the off-pump technique and conventional cardiopulmonary bypass. J Thorac Cardiovasc Surg 2003, 125:843-848

57. Chappell D, Hofmann-Kiefer K, Jacob M, Rehm M, Briegel J, Welsch U, Conzen P, Becker BF: TNF-alpha induced shedding of the endothelial glycocalyx is prevented by hydrocortisone and antithrombin. Basic Res Cardiol 2009, 104:78-89

58. Nieuwdorp M, Meuwese MC, Mooij HL, van Lieshout MH, Hayden A, Levi M, Meijers JC, Ince C, Kastelein JJ, Vink H, Stroes ES: Tumor necrosis factor-alpha inhibition protects against endotoxin-induced endothelial glycocalyx perturbation. Atherosclerosis 2009, 202:296-303

59. Bruegger D, Schwartz L, Chappell D, Jacob M, Rehm M, Vogeser M, Christ F, Reichart B, Becker BF: Release of atrial natriuretic peptide precedes shedding of the endothelial glycocalyx equally in patients undergoing on- and off-pump coronary artery bypass surgery. Basic Res Cardiol 2011, 106:1111-1121

60. Bruegger D, Jacob M, Rehm M, Loetsch M, Welsch U, Conzen P, Becker BF: Atrial natriuretic peptide induces shedding of endothelial glycocalyx in coronary vascular bed of guinea pig hearts. Am J Physiol Heart Circ Physiol 2005, 289:H1993-H1999

61. Chappell D, Bruegger D, Potzel J, Jacob M, Brettner F, Vogeser M, Conzen P, Becker BF, Rehm M: Hypervolemia increases release of atrial natriuretic peptide and shedding of the endothelial glycocalyx. Crit Care 2014, 18:538

62. Becker BF, Jacob M, Leipert S, Salmon AH, Chappell D: Degradation of the endothelial glycocalyx in clinical settings: searching for the sheddases. Br J Clin Pharmacol 2015, 80:389-402

63. Haeger SM, Yang Y, Schmidt EP: Heparan sulfate in the developing, healthy, and injured lung. Am J Respir Cell Mol Biol 2016, 55:5-11

64. Yang Y, Schmidt EP: The endothelial glycocalyx: an important regulator of the pulmonary vascular barrier. Tissue Barriers 2013, 1:e23494

65. Smits NC, Robbesom AA, Versteeg EM, van de Westerlo EM, Dekhuijzen PN, van Kuppevelt TH: Heterogeneity of heparan sulfates in human lung. Am J Respir Cell Mol Biol 2004, 30:166-173

66. Inagawa R, Okada H, Takemura G, Suzuki K, Takada C, Yano H, Ando Y, Usui T, Hotta Y, Miyazaki N, Tsujimoto A, Zaikokuji R, Matsumoto A, Kawaguchi T, Doi T, Yoshida T, Yoshida S, Kumada K, Ushikoshi H, Toyoda I, Ogura S: Ultrastructural alteration of pulmonary capillary endothelial glycocalyx during endotoxemia. Chest 2018, 154:317-325

67. Cao R-N, Tang L, Xia Z-Y, Xia R: Endothelial glycocalyx as a potential therapeutic target in organ injuries. Chin Med J 2019, 132: 963-975

68. Schmidt EP, Yang Y, Janssen WJ, Gandjeva A, Perez MJ, Barthel L, Zemans RL, Bowman JC, Koyanagi DE, Yunt ZX, Smith LP, Cheng SS, Overdier KH, Thompson KR, Geraci MW, Douglas IS, Pearse DB, Tuder RM: The pulmonary endothelial glycocalyx regulates neutrophil adhesion and lung injury during experimental sepsis. Nat Med 2012, 18:1217-1223

69. van Golen RF, van Gulik TM, Heger M: The sterile immune response during hepatic ischemia/reperfusion. Cytokine Growth Factor Rev 2012, 23:69-84

70. Zhai Y, Petrowsky H, Hong JC, Busuttil RW, Kupiec-Weglinski JW: Ischaemia-reperfusion injury, in liver transplantation-from bench to bedside. Nat Rev Gastroenterol Hepatol 2013, 10:79-89

71. Bhogal RH, Curbishley SM, Weston CJ, Adams DH, Afford SC: Reactive oxygen species mediate human hepatocyte injury during hypoxia/reoxygenation. Liver Transpl 2010, 16:1303-1313

72. Rubio-Gayosso I, Platts SH, Duling BR: Reactive oxygen species mediate modification of glycocalyx during ischemia-reperfusion injury. Am J Physiol Heart Circ Physiol 2006, 290:H2247-H2256

73. van Golen RF, van Gulik TM, Heger M: Mechanistic overview of reactive species-induced degradation of the endothelial glycocalyx during hepatic ischemia/reperfusion injury. Free Radic Biol Med 2012, 52:1382-1402

74. Barbas AS, Lin L, McRae M, MacDonald AL, Truong T, Yang YP, Brennan TV: Heparan sulfate is a plasma biomarker of acute cellular allograft rejection. PLoS One 2018, 13:e200877

75. Adepu S, Katta K, Tietge UJ, Kwakernaak AJ, Dam W, van Goor H, Dullaart RP, Navis GJ, Bakker SJ, van den Born J: Hepatic syndecan1 changes associate with dyslipidemia after renal transplantation. Am J Transplant 2014, 14:2328-2338

76. Nadir Y, Brenner B: Heparanase procoagulant activity in cancer progression. Thromb Res 2016, 140 Suppl 1:S44-S48

77. Roemisch J, Gray E, Hoffmann JN, Wiedermann CJ: Antithrombin: a new look at the actions of a serine protease inhibitor. Blood Coagul Fibrinolysis 2002, 13:657-670

78. Chappell D, Dorfler N, Jacob M, Rehm M, Welsch U, Conzen P, Becker BF: Glycocalyx protection reduces leukocyte adhesion after ischemia/reperfusion. Shock 2010, 34:133-139

79. Rovcanin B, Medic B, Kocic G, Cebovic T, Ristic M, Prostran M: Molecular dissection of renal ischemia-reperfusion: oxidative stress and cellular events. Curr Med Chem 2016, 23:1965-1980

80. Masola V, Zaza G, Gambaro G, Onisto M, Bellin G, Vischini G, Khamaysi I, Hassan A, Hamoud S, Nativ O, Heyman SN, Lupo A, 
Vlodavsky I, Abassi Z: Heparanase: a potential new factor involved in the renal epithelial mesenchymal transition (EMT) induced by ischemia/reperfusion (I/R) injury. PLoS One 2016, 11:e0160074

81. Celie JW, Katta KK, Adepu S, Melenhorst WB, Reijmers RM, Slot EM, Beelen RH, Spaargaren M, Ploeg RJ, Navis G, van der Heide JJ, van Dijk MC, van Goor H, van den Born J: Tubular epithelial syndecan-1 maintains renal function in murine ischemia/reperfusion and human transplantation. Kidney Int 2012, 81:651-661

82. Chen H, Ambadapadi S, Wakefield D, Bartee M, Yaron JR, Zhang L, Archer-Hartmann SA, Azadi P, Burgin M, Borges C, Zheng D, Ergle K, Muppala V, Morshed S, Rand K, Clapp W, Proudfoot A, Lucas A: Selective deletion of heparan sulfotransferase enzyme, Ndst1, in donor endothelial and myeloid precursor cells significantly decreases acute allograft rejection. Sci Rep 2018, 8:13433

83. Celie JW, Rutjes NW, Keuning ED, Soininen R, Heljasvaara R, Pihlajaniemi T, Drager AM, Zweegman S, Kessler FL, Beelen RH, Florquin S, Aten J, van den Born J: Subendothelial heparan sulfate proteoglycans become major L-selectin and monocyte chemoattractant protein-1 ligands upon renal ischemia/reperfusion. Am J Pathol 2007, 170:1865-1878

84. Shafat I, Agbaria A, Boaz M, Schwartz D, Baruch R, Nakash R, Ilan N, Vlodavsky I, Weinstein T: Elevated urine heparanase levels are associated with proteinuria and decreased renal allograft function. PLoS One 2012, 7:e44076

85. Sladden TM, Yerkovich S, Grant M, Zhang F, Liu X, Trotter M, Hopkins P, Linhardt RJ, Chambers DC: Endothelial glycocalyx shedding predicts donor organ acceptability and is associated with primary graft dysfunction in lung transplant recipients. Transplantation 2018, 103:1277-1285

86. Hartmann M, Szalai C, Saner FH: Hemostasis in liver transplantation: pathophysiology, monitoring, and treatment. World J Gastroenterol 2016, 22:1541-1550

87. Granger DN, Kvietys PR: Reperfusion injury and reactive oxygen species: the evolution of a concept. Redox Biol 2015, 6:524-551

88. Weinbroum A, Nielsen VG, Tan S, Gelman S, Matalon S, Skinner KA, Bradley E Jr, Parks DA: Liver ischemia-reperfusion increases pulmonary permeability in rat: role of circulating xanthine oxidase. Am J Physiol 1995, 268:G988-G996

89. Manchanda K, Kolarova H, Kerkenpass C, Mollenhauer M, Vitecek J, Rudolph V, Kubala L, Baldus S, Adam M, Klinke A: MPO (myeloperoxidase) reduces endothelial glycocalyx thickness dependent on its cationic charge. Arterioscler Thromb Vasc Biol 2018, 38 : 1859-1867

90. Singh A, Ramnath RD, Foster RR, Wylie EC, Friden V, Dasgupta I, Haraldsson B, Welsh GI, Mathieson PW, Satchell SC: Reactive oxygen species modulate the barrier function of the human glomerular endothelial glycocalyx. PLoS One 2013, 8:e55852

91. Wang Y, Herrera AH, Li Y, Belani KK, Walcheck B: Regulation of mature ADAM17 by redox agents for L-selectin shedding. J Immunol 2009, 182:2449-2457

92. Seal JB, Gewertz BL: Vascular dysfunction in ischemia-reperfusion injury. Ann Vasc Surg 2005, 19:572-584

93. Bernfield M, Gotte M, Park PW, Reizes O, Fitzgerald ML, Lincecum J, Zako M: Functions of cell surface heparan sulfate proteoglycans. Annu Rev Biochem 1999, 68:729-777

94. Vlodavsky I, Friedmann Y, Elkin M, Aingorn H, Atzmon R, IshaiMichaeli R, Bitan M, Pappo O, Peretz T, Michal I, Spector L, Pecker I: Mammalian heparanase: gene cloning, expression and function in tumor progression and metastasis. Nat Med 1999, 5: 793-802

95. Vlodavsky I, Beckhove P, Lerner I, Pisano C, Meirovitz A, Ilan N, Elkin M: Significance of heparanase in cancer and inflammation. Cancer Microenviron 2012, 5:115-132

96. Goldberg R, Rubinstein AM, Gil N, Hermano E, Li JP, van der Vlag J, Atzmon R, Meirovitz A, Elkin M: Role of heparanase-driven inflammatory cascade in pathogenesis of diabetic nephropathy. Diabetes $2014,63: 4302-4313$
97. Wang F, Pulinilkunnil T, Flibotte S, Nislow C, Vlodavsky I, Hussein B, Rodrigues B: Heparanase protects the heart against chemical or ischemia/reperfusion injury. J Mol Cell Cardiol 2019, 131:29-40

98. Zhang D, Wang F, Lal N, Chiu AP, Wan A, Jia J, Bierende D, Flibotte S, Sinha S, Asadi A, Hu X, Taghizadeh F, Pulinilkunnil T, Nislow C, Vlodavsky I, Johnson JD, Kieffer TJ, Hussein B, Rodrigues B: Heparanase overexpression induces glucagon resistance and protects animals from chemically induced diabetes. Diabetes 2017, 66:45-57

99. Pranskunas A, Tamosuitis T, Balciuniene N, Damanskyte D, Sneider E, Vitkauskiene A, Sirvinskas E, Pilvinis V, Boerma EC: Alterations of conjunctival glycocalyx and microcirculation in nonseptic critically ill patients. Microvasc Res 2018, 118:44-48

100. Broekhuizen LN, Mooij HL, Kastelein JJP, Stroes ESG, Vink H, Nieuwdorp M: Endothelial glycocalyx as potential diagnostic and therapeutic target in cardiovascular disease. Curr Opin Lipidol 2009, 20:57-62

101. Aykut G, Veenstra G, Scorcella C, Ince C, Boerma C: Cytocam-IDF (incident dark field illumination) imaging for bedside monitoring of the microcirculation. Intensive Care Med Exp 2015, 3:40

102. Haeren RHL, Rijkers K, Schijns O, Dings J, Hoogland G, van Zandvoort M, Vink H, van Overbeeke JJ: In vivo assessment of the human cerebral microcirculation and its glycocalyx: a technical report. J Neurosci Methods 2018, 303:114-125

103. Cerny V, Astapenko D, Burkovskiy I, Hyspler R, Ticha A, Trevors MA, Lehmann C: Glycocalyx in vivo measurement. Clin Hemorheol Microcirc 2017, 67:499-503

104. Kurzelewski M, Czarnowska E, Beresewicz A: Superoxide- and nitric oxide-derived species mediate endothelial dysfunction, endothelial glycocalyx disruption, and enhanced neutrophil adhesion in the post-ischemic guinea-pig heart. J Physiol Pharmacol 2005, 56: $163-178$

105. Czarnowska E, Karwatowska-Prokopczuk E: Ultrastructural demonstration of endothelial glycocalyx disruption in the reperfused rat heart. Involvement of oxygen free radicals. Basic Res Cardiol 1995, 90:357-364

106. Chappell D, Jacob M, Hofmann-Kiefer K, Rehm M, Welsch U, Conzen P, Becker BF: Antithrombin reduces shedding of the endothelial glycocalyx following ischaemia/reperfusion. Cardiovasc Res 2009, 83:388-396

107. Chappell D, Jacob M, Hofmann-Kiefer K, Bruegger D, Rehm M, Conzen P, Welsch U, Becker BF: Hydrocortisone preserves the vascular barrier by protecting the endothelial glycocalyx. Anesthesiology 2007, 107:776-784

108. Annecke T, Chappell D, Chen C, Jacob M, Welsch U, Sommerhoff CP, Rehm M, Conzen PF, Becker BF: Sevoflurane preserves the endothelial glycocalyx against ischaemia-reperfusion injury. Br J Anaesth 2010, 104:414-421

109. Chen C, Chappell D, Annecke T, Conzen P, Jacob M, Welsch U, Zwissler B, Becker BF: Sevoflurane mitigates shedding of hyaluronan from the coronary endothelium, also during ischemia/reperfusion: an ex vivo animal study. Hypoxia (Auck1) 2016, 4:81-90

110. Lucchinetti E, Ambrosio S, Aguirre J, Herrmann P, Harter L, Keel M, Meier T, Zaugg M: Sevoflurane inhalation at sedative concentrations provides endothelial protection against ischemia-reperfusion injury in humans. Anesthesiology 2007, 106:262-268

111. Vink H, Duling BR: Capillary endothelial surface layer selectively reduces plasma solute distribution volume. Am J Physiol Heart Circ Physiol 2000, 278:H285-H289

112. Jacob M, Bruegger D, Rehm M, Welsch U, Conzen P, Becker BF: Contrasting effects of colloid and crystalloid resuscitation fluids on cardiac vascular permeability. Anesthesiology 2006, 104:1223-1231

113. Jacob M, Paul O, Mehringer L, Chappell D, Rehm M, Welsch U, Kaczmarek I, Conzen P, Becker BF: Albumin augmentation improves condition of guinea pig hearts after $4 \mathrm{hr}$ of cold ischemia. Transplantation 2009, 87:956-965 
114. Yin J, Chen W, Ma F, Lu Z, Wu R, Zhang G, Wang N, Wang F: Sulodexide pretreatment attenuates renal ischemia-reperfusion injury in rats. Oncotarget 2017, 8:9986-9995

115. Lauver DA, Booth EA, White AJ, Poradosu E, Lucchesi BR: Sulodexide attenuates myocardial ischemia/reperfusion injury and the deposition of C-reactive protein in areas of infarction without affecting hemostasis. J Pharmacol Exp Ther 2005, 312: 794-800

116. Spiess BD: Heparin: effects upon the glycocalyx and endothelial cells. J Extra Corpor Technol 2017, 49:192-197

117. Uhl B, Zuchtriegel G, Puhr-Westerheide D, Praetner M, Rehberg M, Fabritius M, Hessenauer M, Holzer M, Khandoga A, Furst R, Zahler S, Krombach F, Reichel CA: Tissue plasminogen activator promotes postischemic neutrophil recruitment via its proteolytic and nonproteolytic properties. Arterioscler Thromb Vasc Biol 2014, 34: 1495-1504

118. Nieuwdorp M, Holleman F, de Groot E, Vink H, Gort J, Kontush A, Chapman MJ, Hutten BA, Brouwer CB, Hoekstra JB, Kastelein JJ, Stroes ES: Perturbation of hyaluronan metabolism predisposes patients with type 1 diabetes mellitus to atherosclerosis. Diabetologia 2007, 50:1288-1293

119. Lygizos MI, Yang Y, Altmann CJ, Okamura K, Hernando AA, Perez MJ, Smith LP, Koyanagi DE, Gandjeva A, Bhargava R,
Tuder RM, Faubel S, Schmidt EP: Heparanase mediates renal dysfunction during early sepsis in mice. Phys Rep 2013, 1:e00153

120. Andreozzi GM: Sulodexide in the treatment of chronic venous disease. Am J Cardiovasc Drugs 2012, 12:73-81

121. Hoppensteadt DA, Fareed J: Pharmacological profile of sulodexide. Int Angiol 2014, 33:229-235

122. Weiss R, Niecestro R, Raz I: The role of sulodexide in the treatment of diabetic nephropathy. Drugs 2007, 67:2681-2696

123. Gaddi AV, Cicero AF, Gambaro G: Nephroprotective action of glycosaminoglycans: why the pharmacological properties of sulodexide might be reconsidered. Int J Nephrol Renovasc Dis 2010, 3:99-105

124. Schmidt A, Echtermeyer F, Alozie A, Brands K, Buddecke E: Plasmin- and thrombin-accelerated shedding of syndecan-4 ectodomain generates cleavage sites at Lys(114)-Arg(115) and Lys(129)Val(130) bonds. J Biol Chem 2005, 280:34441-34446

125. Zeng Y, Adamson RH, Curry FR, Tarbell JM: Sphingosine-1-phosphate protects endothelial glycocalyx by inhibiting syndecan-1 shedding. Am J Physiol Heart Circ Physiol 2014, 306:H363-H372

126. Broekhuizen LN, Lemkes BA, Mooij HL, Meuwese MC, Verberne H, Holleman F, Schlingemann RO, Nieuwdorp M, Stroes ES, Vink H: Effect of sulodexide on endothelial glycocalyx and vascular permeability in patients with type 2 diabetes mellitus. Diabetologia 2010, 53:2646-2655 